UnB - UNIVERSIDADE DE BRASÍLIA FGA - FACULDADE GAMA

PROGRAMA DE PÓS-GRADUAÇÃO EM ENGENHARIA

\title{
BIOMÉDICA
}

\section{DESENVOLVIMENTO DE OBJETO SIMULADOR ANTROPOMÓRFICO DO PÂNCREAS PARA USO EM MEDICINA NUCLEAR}

HALAINE CRISITINE MARIANO SILVA

ORIENTADOR: Dr. Leandro Xavier Cardoso

DISSERTAÇÃO DE MESTRADO EM ENGENHARIA BIOMÉDICA 


\section{UNIVERSIDADE DE BRASILIA \\ FACULDADE UNB GAMA \\ ENGENHARIA BIOMÉDICA}

\section{DESENVOLVIMENTO DE OBJETO SIMULADOR DE PÂNCREAS PARA USO EM MEDICINA NUCLEAR.}

\section{HALAINE CRISTINE MARIANO SILVA}

DISSERTAÇÃO DE MESTRADO SUBMETIDA À FACULDADE UNB GAMA DA UNIVERSIDADE DE BRASILIA, COMO PARTE DOS REQUISITOS NECESSÁRIOS PARA A OBTENÇÃO DO TÍTULO DE MESTRE EM ENGENHARIA BIOMÉDICA.

APROVADA POR:

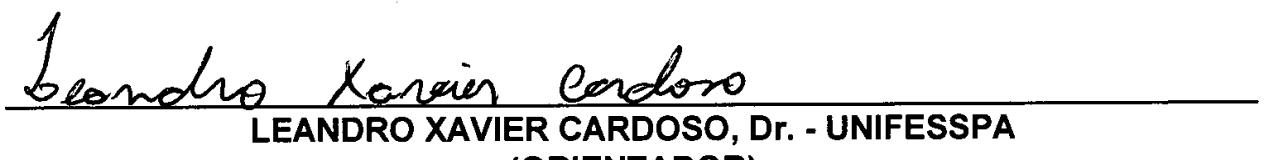
(ORIENTADOR)
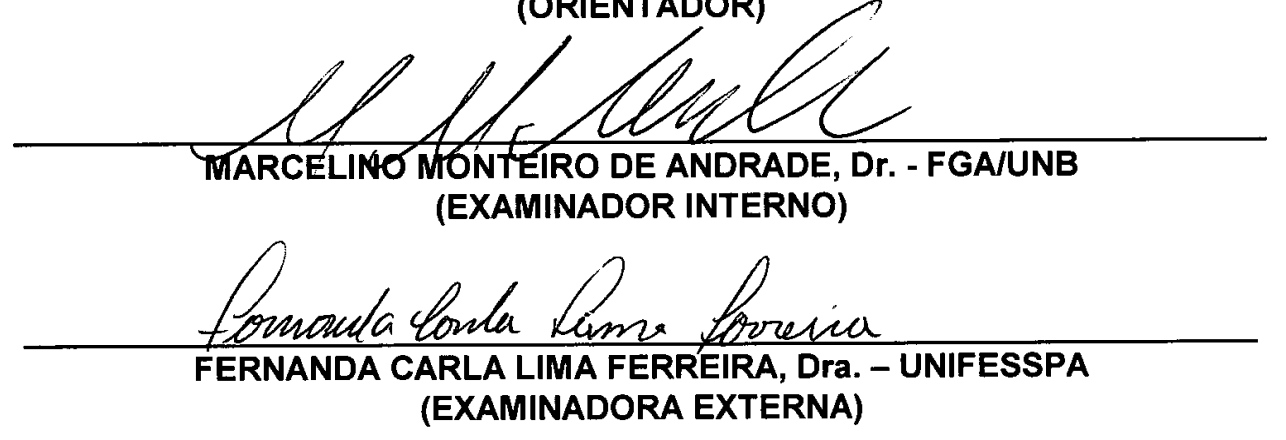

BRASÍLIA, 27 DE FEVEREIRO DE 2015 


\section{FICHA CATALOGRÁFICA}

\section{HALAINE CRISTINE MARIANO SILVA}

DESENVOLVIMENTO DE OBJETO SIMULADOR ANTROPOMÓRFICO DO PÂNCREAS PARA USO EM MEDICINA NUCLEAR, [Distrito Federal] 2015.

No.p. 66, 210 x 297 mm (FGA/UnB Gama, Mestre, Engenharia Biomédica, 2015). Dissertação de Mestrado - Universidade de Brasília. Faculdade Gama. Programa de PósGraduação em Engenharia Biomédica.

1. FÍSICA DAS RADIAÇÕES 2. MEDICINA NUCLEAR

3. OBJETO SIMULADOR

4. CONTROLE DE QUALIDADE

I. FGA UnB Gama/ UnB. II. Título (série)

\section{REFERÊNCIA BIBLIOGRÁFICA}

SILVA, H. C. M. (2015). DESENVOLVIMENTO DE OBJETO SIMULADOR ANTROPOMÓRFICO DO PÂNCREAS PARA USO EM MEDICINA NUCLEAR. Dissertação de Mestrado em Engenharia Biomédica, Publicação 28A/2015, Programa de Pós-Graduação em Engenharia Biomédica, Faculdade Gama, Universidade de Brasília, Brasília, DF, no.p. 66.

\section{CESSÃO DE DIREITOS}

AUTOR: HALAINE CRISITINE MARIANO SILVA.

TÍTULO: DESENVOLVIMENTO DE OBJETO SIMULADOR ANTROPOMÓRFICO DO PÂNCREAS PARA USO EM MEDICINA NUCLEAR

GRAU: Mestre

ANO: 2015

É concedida à Universidade de Brasília permissão para reproduzir cópias desta dissertação de mestrado e para emprestar ou vender tais cópias somente para propósitos acadêmicos e científicos. $\mathrm{O}$ autor reserva outros direitos de publicação e nenhuma parte desta dissertação de mestrado pode ser reproduzida sem a autorização por escrito do autor.

2015

72.444-240, Brasília, DF - Brasil. 


\section{DEDICATÓRIA}

Aos meus pais: Duel Cesar Mariano da Silva e Eva Maria de Jesus Silva. 


\section{AGRADECIMENTOS}

Agradeço ao Professor Orientador Leandro Xavier Cardoso por sua total dedicação e empenho na realização deste trabalho.

À Professora Fernanda Carla Lima Ferreira por sua confiança, dedicação e esclarecimentos.

À Professora Lourdes Mattos Brasil e à Professora Glécia Virgolino da Silva Luz pelo apoio e dedicação na conclusão deste trabalho.

À todos os professores que me acompanharam durante esses 2 anos, em especial ao Professor Marcelino Monteiro de Andrade e ao Professor Georges Daniel Amvame Nze que muito me incentivaram.

Aos responsáveis pelos serviços de Medicina Nuclear do Hospital Santa Marta e do Hospital Universitário de Brasília, em especial ao Professor Araken dos Santos Werneck Rodrigues e ao Dr. Dalton Alexandre dos Anjos.

À todos os colegas pela amizade e companheirismo, em especial à Gabriela Freitas e aos colegas Alisson Pirola e Pedro Iwai que sempre me apoiaram e se tornaram grandes amigos.

À minha família pela compreensão e incentivo.

Ao meu namorado Agnaldo Rosa de Almeida pelo apoio, amizade e companheirismo.

À Coordenação de Aperfeiçoamento de Pessoal de Nível Superior (CAPES) pelo apoio financeiro. 


\title{
RESUMO
}

\section{DESENVOLVIMENTO DE OBJETO SIMULADOR ANTROPOMÓRFICO DO PÂNCREAS PARA USO EM MEDICINA NUCLEAR}

\author{
Autor: HALAINE CRISTINE MARIANO SILVA \\ Orientador: Prof. Dr. Leandro Xavier Cardoso \\ Programa de Pós-Graduação em Engenharia Biomédica \\ Brasília, Fevereiro de 2015.
}

Atualmente, diversos procedimentos clínicos envolvem a utilização das radiações ionizantes fazendo com que a física das radiações se torne indispensável na medicina moderna. Na Medicina Nuclear, por exemplo, são utilizados os chamados radiofármacos para as finalidades de diagnóstico e tratamento de enfermidades. Especificamente, no diagnóstico, é importante que as imagens revelem, com maior precisão possível, detalhes relevantes sobre qualquer anomalia detectada. Neste aspecto, os objetos simuladores tem um papel importante na otimização do controle de qualidade nas câmaras de cintilação. Conforme a norma CNEN NE 3.05, são utilizados objetos simuladores físicos e antropomórficos (ambos para simular e estudar o comportamento das radiações no corpo) adequados para estimativa de imagens médicas e que possibilitem o controle e ajuste da dose absorvida para que a exposição do paciente seja minimizada. Neste sentido, este trabalho justifica-se pela extrema importância do controle e da garantia de qualidade em Medicina Nuclear para que todos os procedimentos clínicos sejam realizados conforme normas estabelecidas e padrões especificados por órgãos competentes. Atendendo, ainda, o interesse dos profissionais de medicina nuclear, este trabalho visa o desenvolvimento de objetos simuladores antropomórficos do pâncreas para testes de controle de qualidade, radioproteção e treinamento de profissionais. Além disso, é interessante que os objetos simuladores possam ser produzidos nacionalmente, que apresentem baixo custo comparado aos importados, que sejam fáceis de reproduzir e, futuramente, estejam disponíveis para diversos serviços de medicina nuclear. Os estudos realizados por este trabalho demonstraram que o objeto simulador antropomórfico de pâncreas confeccionado poderá ser utilizado para avaliação de equipamentos de aquisição de imagem, em especial para testes de resolução espacial, assim como para treinamento de profissionais.

Palavras-chaves: Física das Radiações, Medicina Nuclear, Objeto Simulador e Controle de Qualidade. 
ABSTRACT

DEVELOPMENT OF AN ANTHROPOMORPHIC PANCREAS PHANTOM FOR USE IN NUCLEAR MEDICINE

\section{Author: HALAINE CRISTINE MARIANO SILVA}

Supervisor: Dr. Leandro Xavier Cardoso

Post-Graduation Program in Biomedical Engineering

Brasília, February of 2015.

Currently, several clinical procedures involving the use of ionizing radiation causing radiation physics have become indispensable in modern medicine. In nuclear medicine, for example, so-called radiopharmaceuticals for diagnostic purposes and treatment of diseases, are used. Specifically, the diagnosis, it is important that the images show, with maximum precision, relevant details of any detected anomaly. In this respect, the objects simulators has an important role in optimizing the quality control in scintillation cameras. According to the standard CNEN NE 3.05 are used objects and anthropomorphic physical simulators (both to simulate and study the behavior of radiation in the body) suitable for estimation of medical images and enable the control and dose adjustment absorbed into the patient's exposure is minimized. Thus, this work is justified by the extreme importance of control and quality assurance in nuclear medicine for all clinical procedures are performed according to established and standards specified by relevant standards bodies. Given also the interest of nuclear medicine professionals this work aims at the development of anthropomorphic phantoms of the pancreas for quality control testing, radiation protection and training professionals. Moreover, it is interesting that the objects simulators can be produced nationally, that represent a low cost compared to imports, which are easy to play and in the future, are available for many nuclear medicine services. The studies have demonstrated by this work that the object made pancreas anthropomorphic simulator can be used to evaluate image acquisition devices, in particular for spatial resolution tests, as well as for professional training.

Key-words: Radiation Physics, Nuclear Medicine, Simulator Object and Quality Control. 


\section{SUMÁRIO}

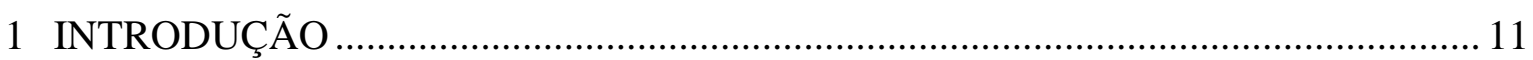

1.1 CONTEXTUALIZAÇÃO E FORMULAÇÃO DO PROBLEMA............................ 11

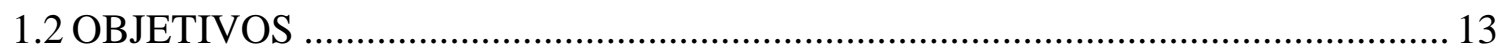

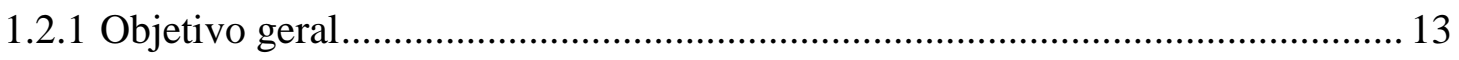

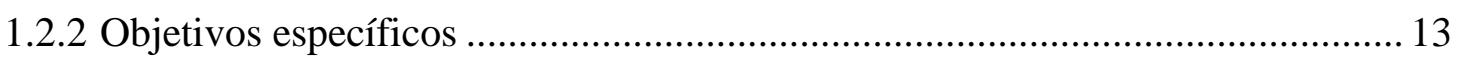

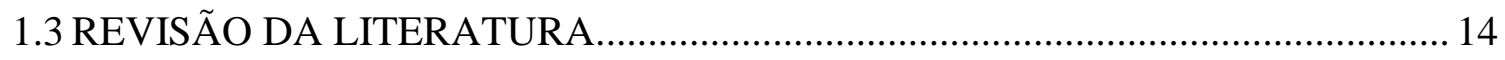

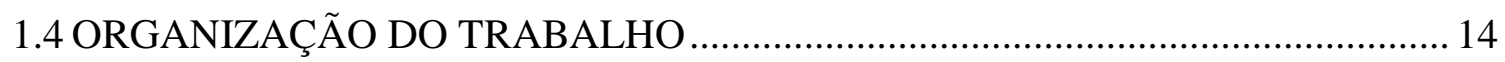

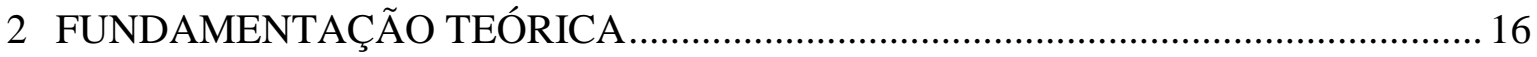

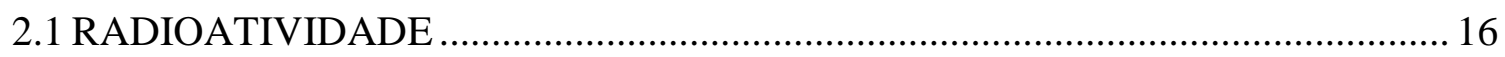

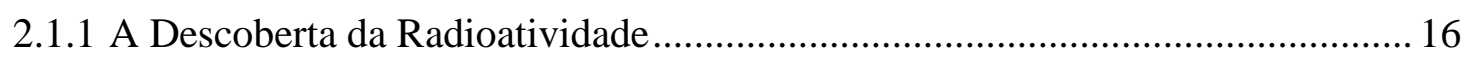

2.1.2 Instabilidade Nuclear e Decaimento Radioativo............................................... 19

2.2 INTERAÇÃO DA RADIAÇÃO COM A MATÉRIA .............................................. 25

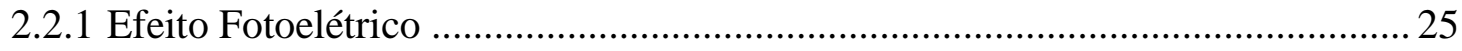

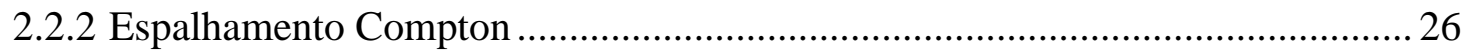

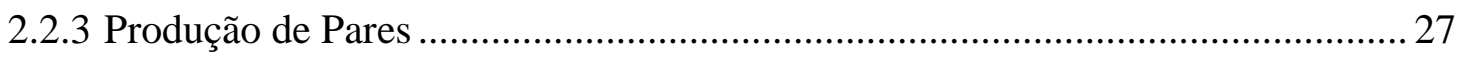

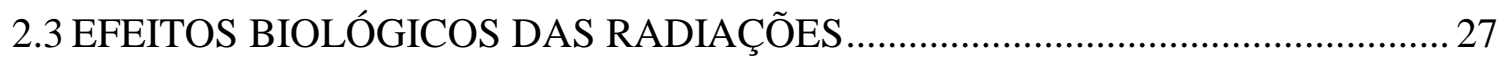

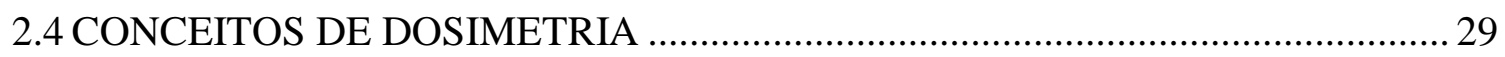

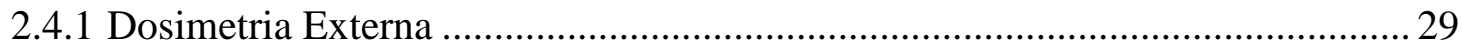

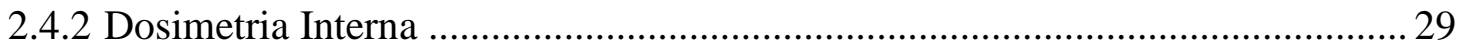

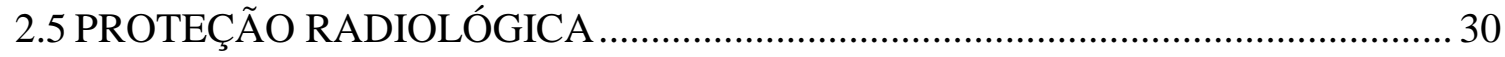

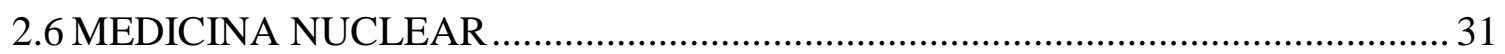

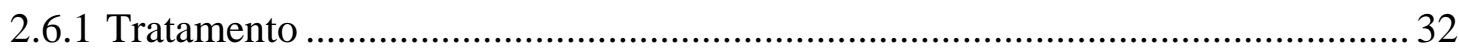

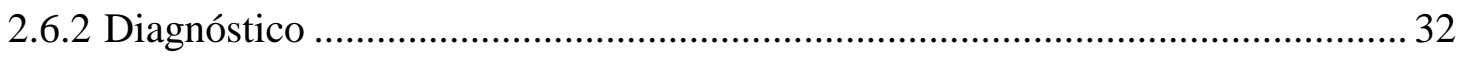

2.6.3 Preparações Radiofarmacêuticas......................................................................... 33

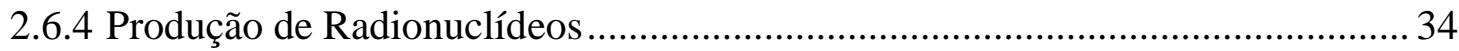

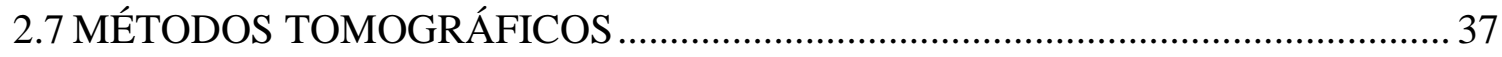

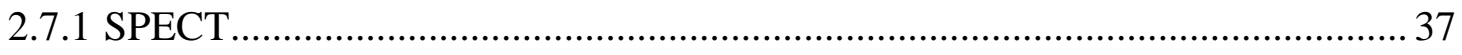

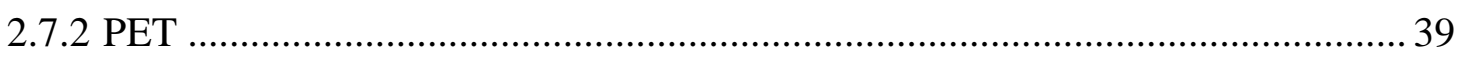

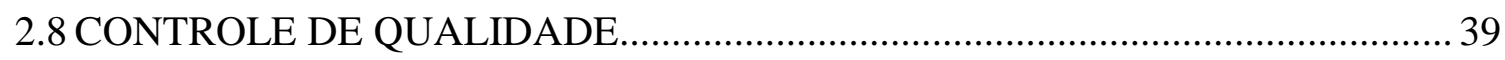

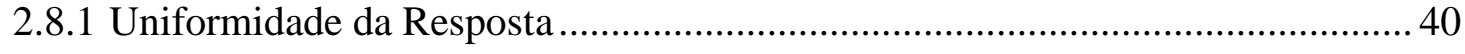

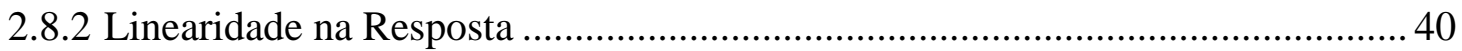

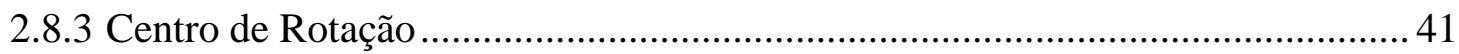




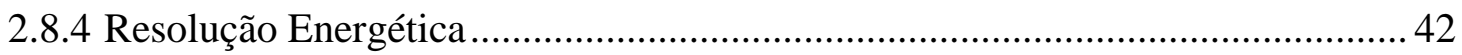

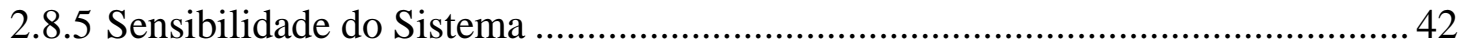

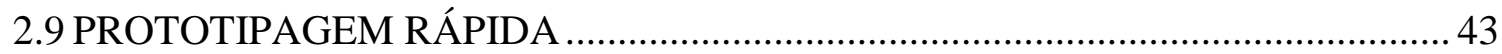

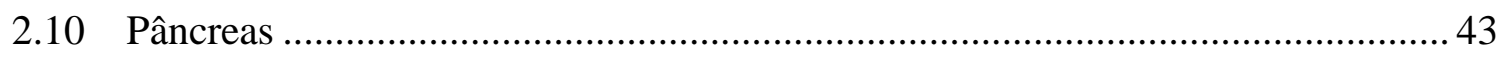

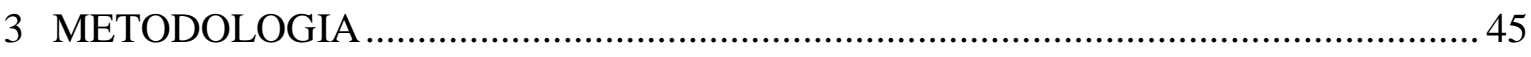

3.1. PROCEDIMENTOS PARA REALIZAÇÃO DOS TESTES .................................. 48

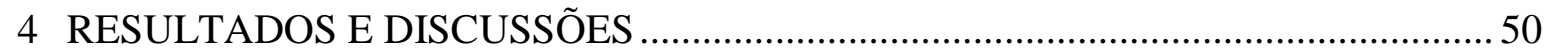

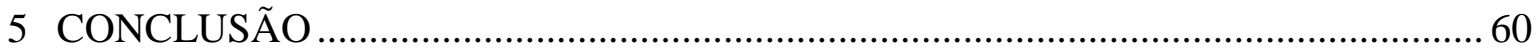

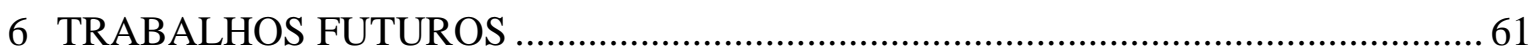

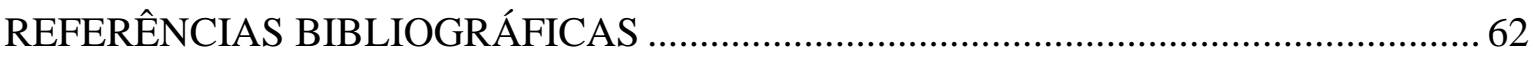

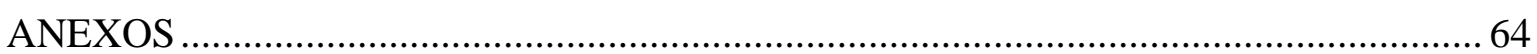




\section{LISTA DE TABELAS}

Tabela 1: Limites de Doses Anuais (mSv) estabelecidos ................................................. 31

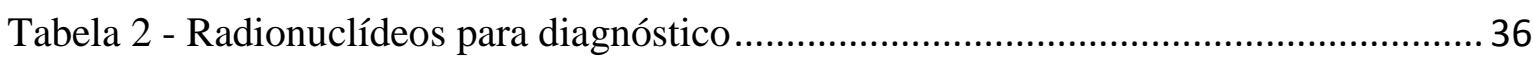

Tabela 3: Resultados obtidos no teste de Centro de Rotação ................................................ 55 


\section{LISTA DE FIGURAS}

Figura 1 - Radiografia tirada por Röntgen em 22 de dezembro de 1895 e apresentada ao professor Ludwig Zehnder, do instituto de física da Universidade de Freiburg, em 1 de Janeiro de 1896.

Figura 2 - Radiografia com o contorno dos dois cristais de sulfato duplo de urânio e potássio, e de uma cruz de cobre interposta entre um dos cristais e o filme. As anotações são do próprio Becquerel.

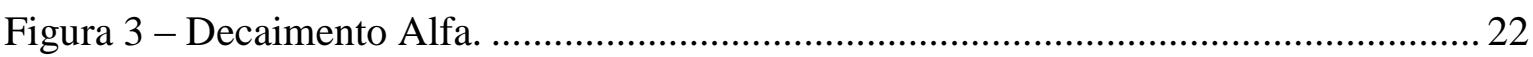

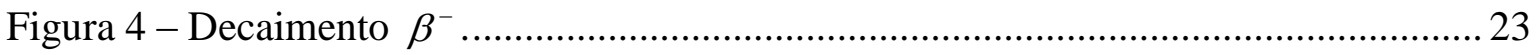

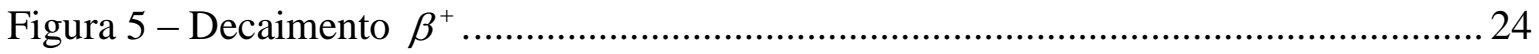

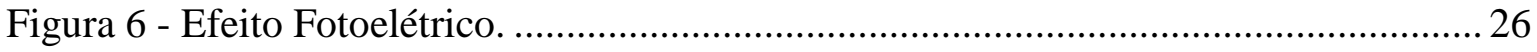

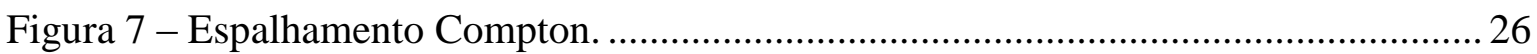

Figura 8 - Reação de Aniquilação.............................................................................. 27

Figura 9 - Gerador ${ }^{99} \mathrm{Mo} /{ }^{99 m} \mathrm{Tc}$. O gerador é constituído por uma coluna de Alumina na qual está adsorvido o radionuclídeo "pai” ( ${ }^{99} \mathrm{Mo}$ ) na forma química de $\mathrm{MoO}_{4}^{2-}$. Por eluição com soro fisiológico é apenas eluído o ${ }^{99 m} \mathrm{TcO}_{4}^{-}$, recolhido sob vácuo, enquanto o

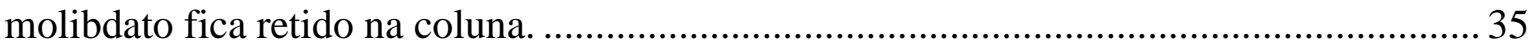

Figura 10 - Componentes da Câmara de Cintilação. .......................................................... 38

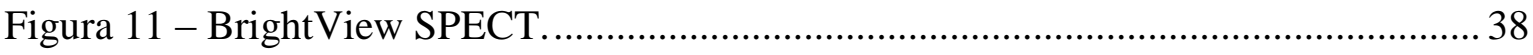

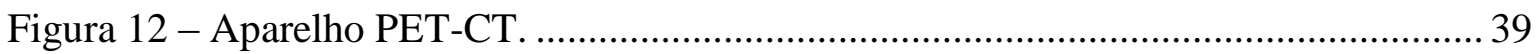

Figura 13 - Objeto Simulador Físico utilizado em testes de linearidade. .......................... 41

Figura 14 - Imagem obtida do Objeto Simulador Físico. ................................................... 41

Figura 15 - Esboço da definição de centro de rotação. ...................................................... 42

Figura 16 - Representação Pictórica do Pâncreas. .............................................................. 44

Figura 17 - Proporções utilizadas de Alginato e Água. .................................................... 45

Figura 18 - Distribuição do Acrílico no Molde de Alginato.............................................. 46

Figura 19 - Phantom do Pâncreas Desenvolvido na UNIFESSPA..................................... 46

Figura 20 - Modelo do Pâncreas confeccionado na impressora 3D.................................. 47

Figura 21 - Segundo protótipo do Objeto Simulador antropomórfico do Pâncreas. ........... 48

Figura 22 - Radiografia do phantom do pâncreas........................................................... 50

Figura 23 - Imagens Estáticas (Anterior/Posterior) do Phantom do Pâncreas..................... 51

Figura 24 - Imagem cintilográfica do primeiro protótipo do Phantom do Pâncreas. .......... 52

Figura 25 - Imagem dos simuladores de hemangioma. ....................................................... 53

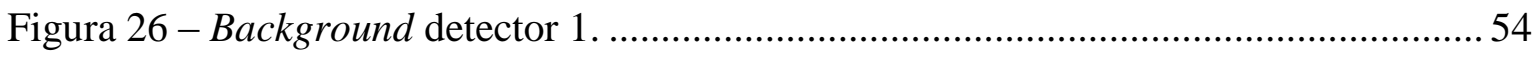

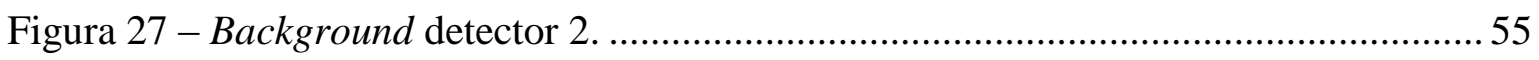

Figura 28 - Gráfico apresentando o resultado do teste de Centro de Rotação..................... 56

Figura 29 - Gráfico apresentando a curva energética do detector 1. .................................57

Figura 30 - Imagens estáticas (Anterior/Posterior) do segundo protótipo do objeto simulador do Pâncreas. 


\section{LISTA DE SÍMBOLOS, NOMENCLATURAS E ABREVIAÇÕES}

AAPM - American Association of Physicists in Medicine

ABS - Acrilonitrila Butadieno Estireno

CAD - Computer-aided design

CBR - Colégio Brasileiro de Radiologia

CNEN - Comissão Nacional de Energia Nuclear

CQ - Controle de Qualidade

DNA - Deoxyribonucleic Acid

FGA - Faculdade Gama

HUB - Hospital Universitário de Brasília

IAEA - International Atomic Energy Agency

ICRP - International Commission on Radiological Protection

ICRU - International Commission on Radiation Units and Measurements

IEEE - Institute of Electrical and Electronics Engineers

INCA - Instituto Nacional do Câncer

LEI - Laboratório de Engenharia e Inovação

PET - Positron Emission Tomography

RBFM - Revista Brasileira de Física Médica

SI - Sistema Internacional de Unidades

SPECT - Single-Photon Emission Computerized Tomography

UnB - Universidade de Brasília

UNIFESSPA - Universidade Federal do Sul e Sudeste do Pará 


\section{INTRODUÇÃO}

\subsection{CONTEXTUALIZAÇÃO E FORMULAÇÃO DO PROBLEMA}

Logo após a descoberta da radioatividade, os efeitos causados pela interação das radiações com as estruturas vivas estimularam diversas pesquisas relacionadas à sua aplicação no diagnóstico e tratamento de várias doenças. Atualmente, diversos procedimentos clínicos fazem uso das radiações ionizantes elevando a física das radiações à condição de indispensável na medicina moderna (OKUNO, 2010).

A descoberta dos chamados traçadores radioativos, em 1913 pelo químico George de Hevesy, foi um dos grandes avanços proporcionados para a medicina nuclear (THRALL, 2003). Desde então, essa especialidade médica está se desenvolvendo cada vez mais, principalmente após o surgimento dos Cíclotrons (aceleradores de partículas) e de reatores nucleares que possibilitaram a produção de diversos radiotraçadores que hoje são utilizados com bastante frequência na Medicina Nuclear, seja no diagnóstico e/ou tratamento de várias enfermidades (CHERRY, 2003).

No diagnóstico, a aplicação dos radiotraçadores objetiva detectar e verificar a extensão da patologia. Para o diagnóstico em Medicina Nuclear, são utilizados radiofármacos que possuem em sua composição radionuclídeos emissores de radiação gama $(\gamma)$ ou emissores de pósitrons $\left(\beta^{+}\right)$(OLIVEIRA, 2006). Os radiofármacos são introduzidos no corpo do paciente e atingem os tecidos, órgãos ou sistema que se deseja analisar. Ao atingirem o local específico, sofrem decaimento e emitem radiações que são detectadas fora do organismo, formando, então, as imagens que permitem o diagnóstico de várias doenças (CHERRY, 2003).

Para a obtenção de imagens, são utilizados os chamados tomógrafos, que são equipamentos com a finalidade de selecionar a radiação emitida pelo radiofármaco previamente administrado no paciente. Existem, essencialmente, dois tipos de exames tomográficos - SPECT (Single-Photon Emission Computerized Tomography) e PET (Positron Emission Tomography). Para estes tipos de exames, intenta-se que o radionuclídeo tenha tempo de meia-vida suficientemente curto para minimizar a exposição do paciente à radiação e suficientemente longo para adquirir e processar as imagens com acurada definição (OLIVEIRA, 2006). 
Ainda que os benefícios trazidos pela utilização das radiações sejam relevantes para a medicina, seu uso deve ser monitorado criteriosamente devido aos riscos que os pacientes e profissionais da saúde estão sujeitos quando do uso de doses inapropriadas. É neste contexto que o Controle de Qualidade (CQ) nos setores de Medicina Nuclear se torna indispensável, visando sempre minimizar a exposição do paciente durante os procedimentos da medicina diagnóstica que faz uso de radiações (OLIVEIRA, 2013).

Para tanto, alguns testes são considerados essenciais para a garantia da qualidade da imagem médica, tendo por finalidade reduzir ao máximo a dose absorvida pelos pacientes e profissionais dos setores de medicina nuclear (FERREIRA, 2011). Contudo, para a realização destes testes, é inadmissível que sejam feitos diretamente no corpo humano, uma vez que existem organizações ${ }^{1}$ que objetivam reduzir a exposição do paciente aos efeitos nocivos da radiação ionizante. Além disso, as variações de geometria, morfologia e anatomia do organismo humano fariam com que a análise dos testes fosse bastante complexa (CERQUEIRA, 2011).

Neste contexto, os objetos simuladores (phantoms) tem um papel importante na otimização do controle de qualidade nas câmaras de cintilação (também chamadas gamacâmaras), garantindo que a obtenção de imagens seja confiável para o diagnóstico e a radiação utilizada seja eficiente para um processamento das imagens com qualidade e definição (FURNARI, 2009).

Conforme a norma CNEN NE 3.05 (CNEN, 2013) são utilizados objetos simuladores físicos e antropomórficos adequados para realização dos testes de uniformidade de campo, linearidade e resolução espacial das câmaras cintilográficas (FERREIRA, 2011). Estes objetos podem possuir geometria simples (objeto simulador físico), confeccionados no formato de caixas, ou podem possuir geometria semelhante à forma real do órgão (objeto simulador antropomórfico). Ambos são utilizados para simular e estudar o comportamento das radiações no corpo e, assim, fazer estimativa de imagens médicas, além de possibilitar controle e ajuste da dose absorvida para que a exposição do paciente seja minimizada (CERQUEIRA, 2011).

\footnotetext{
${ }^{1}$ No Brasil, a Comissão Nacional de Energia Nuclear (CNEN) é responsável pelo controle do uso de radiação ionizante nos setores de Medicina Nuclear.
} 
Tendo como instigação a importância do estudo das radiações envolvidas em procedimentos de radiodiagnósticos, além dos objetivos que serão especificados na próxima seção, o objetivo principal deste trabalho é desenvolver objetos simuladores antropomórficos do pâncreas para uso em medicina nuclear. A escolha do órgão está fundamentada em vários aspectos. Entre eles, inclui-se o aumento no número de pacientes diagnosticados com tumores no pâncreas, já em estágio avançado (INCA, 2006). É relevante mencionar, ainda, a importância deste órgão nas funções digestivas e endócrinas (secreta hormônios, como glucagon e insulina, responsáveis pela regulação normal do metabolismo da glicose, proteínas e lipídeos).

Logo, este trabalho justifica-se pela extrema importância do controle e da garantia de qualidade em Medicina Nuclear para que todos os procedimentos clínicos sejam realizados conforme normas estabelecidas e padrões especificados por órgãos competentes.

Atendendo, ainda, o interesse dos profissionais de medicina nuclear este trabalho visa o desenvolvimento de objetos simuladores para testes de controle de qualidade em imagens, radioproteção e treinamento de profissionais. Além disso, é interessante que os objetos simuladores possam ser produzidos nacionalmente, que apresentem baixo custo comparado aos importados, que sejam fáceis de reproduzir e, futuramente, estejam disponíveis para diversos serviços de medicina nuclear.

\subsection{OBJETIVOS}

\subsubsection{Objetivo geral}

Este trabalho tem por objetivo principal desenvolver objetos simuladores antropomórficos do pâncreas para uso em Medicina Nuclear.

\subsubsection{Objetivos específicos}

- Construir objetos simuladores antropomórficos adequados para avaliação do tamanho e funcionamento do pâncreas;

- Reproduzir na impressora 3D um molde para a confecção de um objeto simulador antropomórfico com geometria mais próxima do órgão real;

- Realizar controle de qualidade de imagens obtidas com os phantoms confeccionados; 
- Determinar a frequência e a necessidade de calibração ou de manutenção preventiva dos equipamentos de SPECT a partir da qualidade das imagens obtidas.

\subsection{REVISÃO DA LITERATURA}

Esta pesquisa tem área de atuação em Engenharia Biomédica, com ênfase em Física Médica. O trabalho desenvolveu-se com base nos conhecimentos da Física Nuclear aplicados à Medicina Nuclear.

Vários bancos de dados foram pesquisados durante a realização deste. Pode-se destacar o PubMed, Periódicos Capes e periódicos do Institute of Electrical and Electronics Engineers (IEEE). Periódicos de revistas como Radiology e RadioGraphics, ambas de grande relevância para a área médica, também foram utilizados.

Alguns livros referentes às áreas de Medicina Nuclear, Biofísica, Física das Radiações, Radiologia e Fisiologia Médica também contribuíram para o desenvolvimento dos conceitos chaves. A pesquisa fundamentou-se, também, em normativas da Comissão Nacional de Energia Nuclear (CNEN), Agência Internacional de Energia Atômica (AIEA), International Commission on Radiological Protection (ICRP) e International Commission on Radiation Units and Measurements (ICRU). Eventualmente, apostilas da CNEN e o portal eletrônico do Instituto do Câncer (INCA) também foram acessados.

Alguns artigos sobre o desenvolvimento de objetos simuladores utilizados na medicina nuclear foram encontrados na Revista Brasileira de Física Médica (RBFM) e Colégio Brasileiro de Radiologia (CBR). No entanto, nenhum deles fazia menção ao desenvolvimento de objetos simuladores antropomórfico do pâncreas.

\subsection{ORGANIZAÇÃO DO TRABALHO}

Este trabalho está dividido em 6 capítulos incluindo este. No segundo capítulo foram apresentados alguns conceitos chaves sobre física das radiações, Medicina Nuclear e fisiologia do pâncreas. O terceiro capítulo apresenta a metodologia empregada para o desenvolvimento do objeto simulador antropomórfico do pâncreas e os procedimentos dos testes realizados, enquanto o quarto capítulo apresenta os resultados dos procedimentos realizados com o phantom nos serviços de medicina nuclear. Uma breve discussão foi 
realizada no capítulo 5 acerca dos resultados obtidos e apresentados no capítulo 4 . Por fim, o sexto e último capítulo destaca as possibilidades de trabalhos futuros com este estudo. 


\section{FUNDAMENTAÇÃO TEÓRICA}

Neste tópico serão definidos alguns conceitos importantes sobre radioatividade, bem como a interação da radiação com a matéria, efeitos biológicos das radiações, conceitos de dosimetria e proteção radiológica. Será feita, também, uma breve abordagem sobre medicina nuclear e os métodos tomográficos utilizados para obtenção de imagens nesta especialidade médica.

Comentaremos, ainda, sobre o controle de qualidade em câmara de cintilação e, por fim, faremos um estudo do órgão escolhido para a construção do objeto simulador - o pâncreas.

\subsection{RADIOATIVIDADE}

Alguns experimentos realizados no século XIX permitiram desvendar características da composição da matéria até então desconhecidas. Foi neste contexto que descobertas importantes a respeito da natureza de átomos e moléculas foram obtidas através do estudo da interação da radiação com a matéria (EISBERG,1979).

Neste momento, revisaremos a história da descoberta da radioatividade e sua contribuição para a Física Nuclear.

\subsubsection{A Descoberta da Radioatividade}

O fim do século XIX foi marcante para várias áreas da ciência e, principalmente, para a Medicina Diagnóstica. Foi neste período de grandes descobertas científicas que a física e a medicina, rapidamente, se aliaram. Uma das grandes contribuições da física para a medicina foi a descoberta dos Raios X por Röntgen, em 1895, que ao perceber o poder de penetração deste raio "misterioso", fez uma imagem da mão de sua esposa (Figura 1), revelando as estruturas em termos da luminescência (ou ausência dela) das partes mais (ou menos) densas (GARCIA, 2002).

A descoberta de Röntgen ocorreu durante a realização de experimentos, em uma sala escura, com raios catódicos produzidos pelos tubos de Crookes. Röntgen percebeu que em uma tela coberta com platino-cianeto de bário era projetada uma luminosidade resultante da fluorescência do material. Ele comprovou que a luminescência era causada por raios 
invisíveis e misteriosos, cuja natureza ainda era desconhecida. Por esta razão chamou-os de raios $\mathrm{X}$ (OKUNO, 2010).

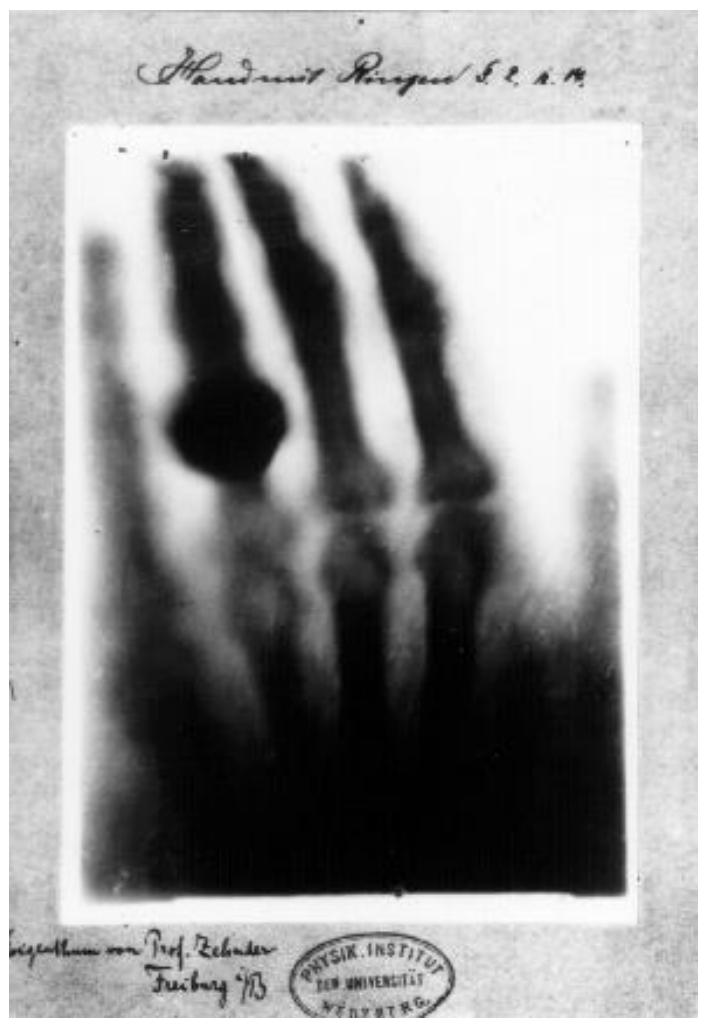

Figura 1 - Radiografia tirada por Röntgen em 22 de dezembro de 1895 e apresentada ao professor Ludwig Zehnder, do instituto de física da Universidade de Freiburg, em 1 de Janeiro de 1896. Fonte: Garcia (2002).

Cerca de um ano após a descoberta dos raios X, Antoine Henry Becquerel, notou que sais de urânio emitiam, espontaneamente, raios que tinham propriedades similares a dos raios X. Becquerel iniciou seus estudos verificando se todos os materiais que emitiam qualquer tipo de luminescência apresentavam também a mesma característica observada nos raios X (OKUNO, 2010).

Para observar essa propriedade, ele realizou uma experiência que consistiu em colocar um material fosforescente sobre uma chapa fotográfica envolvida com papel preto e expor o conjunto ao sol. Ele acreditava que a energia solar era a responsável pela fosforescência. Portanto, os raios emitidos pelo material, na presença de energia solar, seriam capazes de atravessar a proteção de papel e sensibilizar o filme fotográfico (OKUNO, 2010).

Becquerel fracassou em seus primeiros experimentos, mas ao repetir a mesma experiência utilizando $\mathrm{K}_{2}\left(\mathrm{UO}_{2}\right)\left(\mathrm{SO}_{4}\right)_{2}$ - cristais de sulfato duplo de potássio e uranila - 
notou um contorno apagado do cristal ao revelar a chapa fotográfica algumas horas após a exposição à luz solar (OKUNO, 2010).

Entusiasmado com o resultado, resolveu repetir o experimento, mas desta vez, utilizando dois cristais de sulfato duplo de Urânio e Potássio, com uma fina cruz de cobre colocada entre um deles e o filme fotográfico. No entanto, o dia estava nublado, e Becquerel guardou o conjunto em uma gaveta e esperou por um dia ensolarado. Este incidente contribuiu para uma das mais importantes descobertas do século XIX - a radioatividade (OKUNO, 2010).

Como o sol não apareceu, Becquerel resolveu revelar o filme e esperava por manchas bem apagadas (quase imperceptíveis). Porém, foi surpreendido ao se deparar com manchas bem mais escuras e definidas (Figura 2). Ele concluiu, então, que os raios eram emitidos mesmo na ausência de energia solar (OKUNO, 2010).

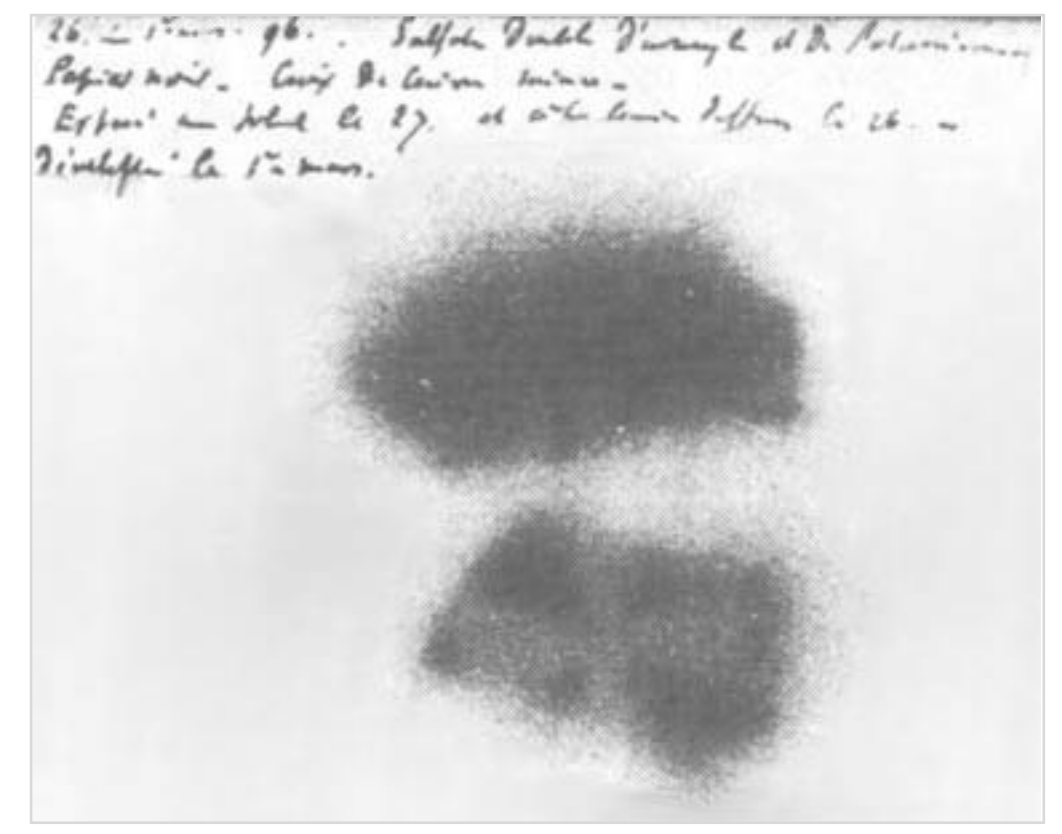

Figura 2 - Radiografia com o contorno dos dois cristais de sulfato duplo de urânio e potássio, e de uma cruz de cobre interposta entre um dos cristais e o filme. As anotações são do próprio Becquerel. Fonte: Okuno (2010).

Logo após sua descoberta, ele relatou que a radiação não estava relacionada à fosforescência, mas sim a sais de Urânio, já que sais de Urânio, não fosforescente, emitiam raios invisíveis com a mesma intensidade que os sais de Urânio fosforescente (OKUNO, 2010). 
Posteriormente, em 1898, Pierre Curie e Marie Sklodowska Curie descobriram a radioatividade natural dos elementos rádio e polônio, sendo que décadas mais tarde o rádio viria a se tornar muito importante na terapia do câncer (GARCIA, 2002).

Em 1899, Ernest Rutherford estudando a radioatividade do urânio, concluiu que existem dois tipos de radiações, uma facilmente absorvida e outra muito mais penetrante. Chamou-as de alfa e beta e percebeu que ambas eram desviadas na presença de campos magnéticos, sugerindo que ambas eram dotadas de carga elétrica (OKUNO, 1982).

Em 1900, Paul Villard descobriu um terceiro tipo de radiação que não sofria desvio na presença de campo magnético, sendo denominado de raios gama. Pouco tempo depois, em 1904, Marie Curie ganhou um segundo prêmio Nobel em Química, após determinar a massa atômica do rádio (GARCIA, 2002).

Até então, não havia nenhuma evidência que estas radiações realmente poderiam ser utilizadas como meio de diagnóstico e/ou tratamento de enfermidades. Estes cientistas estavam desbravando o desconhecido e não sabiam das consequências de suas descobertas para o corpo humano.

\subsubsection{Instabilidade Nuclear e Decaimento Radioativo}

Toda matéria é constituída por estruturas elementares denominadas átomos. O átomo por sua vez, é constituído por um núcleo (formado basicamente por prótons e nêutrons) circundado por elétrons (RUSSEL, 1994).

A maioria dos átomos, na ausência de influências externas, são permanentemente estáveis quanto à estrutura (YOSHIMURA, 2009). Entretanto, quando um átomo possui um núcleo muito energético (com excesso de partículas ou de carga) emite radiação a fim de alcançar a estabilidade. Para que isso aconteça, o núcleo (do átomo "pai”) emite, em forma de radiação (corpuscular ou eletromagnética), partícula e/ou energia, impondo uma mudança na composição do núcleo, dando origem a outro elemento químico, chamado de átomo "filho". Esse processo é chamado decaimento radioativo, ou desintegração radioativa, sendo mais comuns os decaimentos alfa $(\alpha)$, beta $(\beta)$ e gama $(\gamma)$.

O processo de desintegração nuclear é espontâneo e aleatório (OLIVEIRA, 2002). No entanto, para uma dada amostra conhecida com $\mathrm{N}$ núcleos radioativos, a taxa de decaimento é dada pela Equação 1. 


$$
-\frac{d N}{d t}=\lambda N
$$

Em que $\lambda$ é a constante de decaimento e seu valor é diferente para cada núcleo radioativo. A unidade no Sistema Internacional de Unidades (SI) é expressa em Becquerel (Bq) ou Currie (Ci). Um $B q$ equivale a uma desintegração por segundo e um Ci equivale a $3,7 \times 10^{10} \mathrm{~Bq}(\mathrm{OKUNO}, 1982)$.

Separando as variáveis na Equação 1,

$$
\frac{d N}{N}=-\lambda d t
$$

e integrando ambos os lados da Equação 2,

$$
\int \frac{d N}{N}=-\lambda \int d t
$$

pode-se determinar $N$. Desta forma, tem-se:

$$
\ln N=-\lambda t+C
$$

Aplicando a exponencial em ambos os lados da Equação 4:

$$
e^{\ln N}=e^{(-\lambda t+C)}
$$

Logo,

$$
N(t)=C e^{-\lambda t}
$$

Aplicando a condição de contorno para $t=0$ :

$$
N(0)=C \equiv N_{0}
$$

E, então:

$$
N(t)=N_{0} e^{-\lambda t}
$$

em que $N_{0}$ é o número de radionuclídeos no instante inicial $t_{0}$.

A Equação 8 é denominada equação do decaimento radioativo, em que $N$ é o número de radionuclídeos no instante $t>0$.

A taxa de decaimento $R$ pode ser dada por: 


$$
R=\lambda N
$$

Portanto, podemos reescrever a Equação 1 de forma que:

$$
R=-\frac{d N}{d t}
$$

Derivando a Equação 8, tem-se:

$$
R=\lambda N_{0} e^{-\lambda t}
$$

Logo:

$$
R=R_{0} e^{-\lambda t}
$$

Em que $\mathrm{R}_{0}$ é a taxa de decaimento no instante $\mathrm{t}=0$ e $R$ é a taxa de decaimento para o instante $\mathrm{t}>0$.

Uma definição importante na teoria da radioatividade é o tempo de meia vida da amostra $\left(T_{1 / 2}\right)$. Esta definição resulta em um tempo necessário para que a atividade de um determinado radioisótopo se reduza à metade. Esse tempo pode variar para cada radionuclídeo. A equação, em termos da constante de decaimento, pode ser obtida fazendo:

$$
R=\frac{R_{0}}{2}
$$

Substituindo $R$ na Equação 12 e sendo $\mathrm{t}=T_{1 / 2}$, tem-se:

$$
\frac{R_{0}}{2}=R_{0} e^{-\lambda T_{1 / 2}}
$$

Aplicando logaritmo em ambos os termos da equação:

$$
\ln 2=\lambda T_{1 / 2}
$$

Logo,

$$
T_{1 / 2}=\frac{\ln 2}{\lambda}
$$




\section{Decaimento Alfa}

Um átomo instável, ao sofrer desintegração a fim de alcançar a estabilidade, pode liberar três formas principais de radiação: partícula alfa, partícula beta e/ou radiação gama.

O decaimento por partículas alfa consiste em dois prótons e dois nêutrons que, essencialmente, equivale ao núcleo de um átomo de hélio (RUSSEL, 1994). A Figura 3 representa o decaimento $\alpha$.

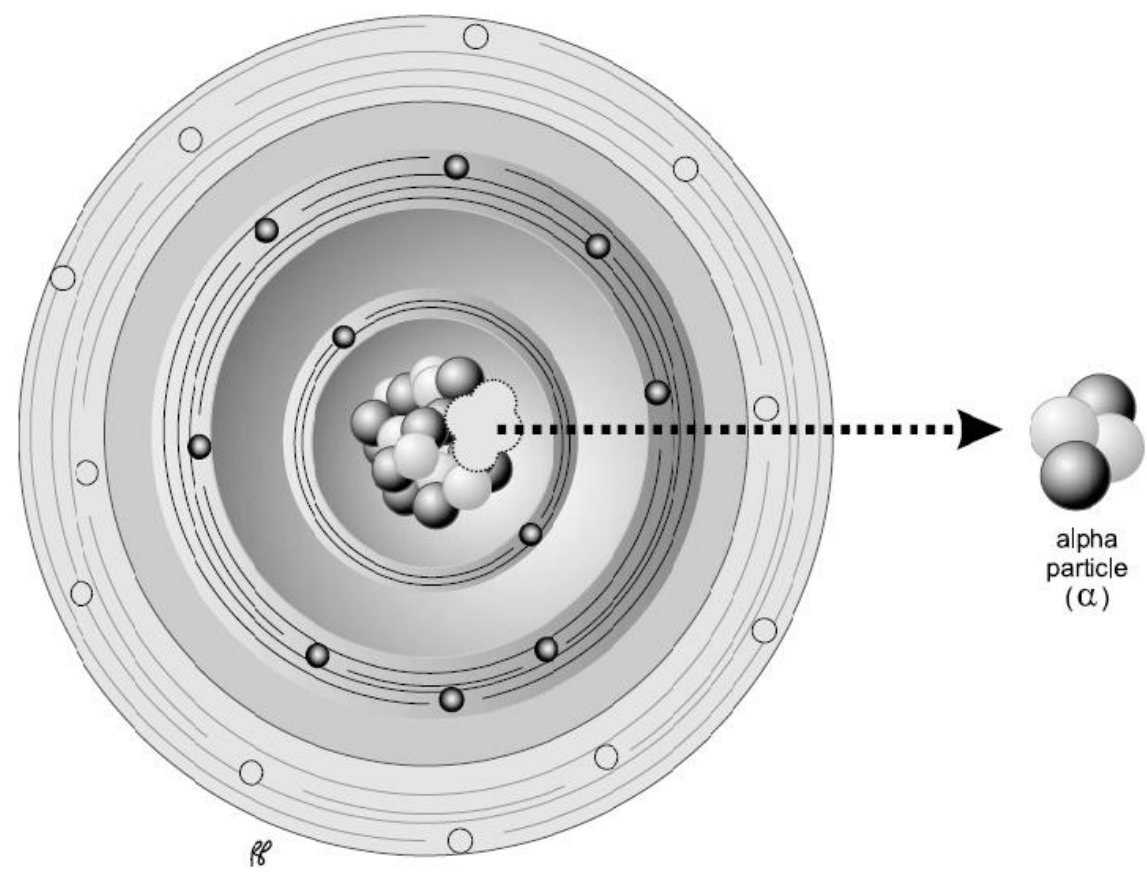

Figura 3 - Decaimento Alfa.

Fonte: Powsner (2006)

O padrão de notação é representado por:

$$
{ }_{Z}^{A} X \stackrel{\alpha}{\longrightarrow}{ }_{Z-2}^{A-4} Y
$$

As partículas $\alpha$, dos três tipos de radiação, são as de menor energia, sendo emitidas com energia cinética, geralmente, entre 4 e $8 \mathrm{MeV}$. Ao interagir com átomos de ar, as partículas $\alpha$ perdem $33 \mathrm{eV}$ por ionização. Portanto, a razão entre a energia cinética e a energia perdida em cada ionização resulta na quantidade de ionização que a partícula produz antes de parar (OKUNO, 1982).

A distância que as partículas $\alpha$ percorrem antes de parar é muito pequena e por isso podem ser blindadas facilmente. Não podem atravessar a pele humana, no entanto, se uma pessoa 
ingerir uma fonte emissora de radiação $\alpha$, provavelmente ocorrerá sérios danos a alguns tecidos vivos (OKUNO, 1982).

\section{Decaimento Beta}

As partículas $\beta$ são elétrons $\left(\beta^{-}\right)$e pósitrons $\left(\beta^{+}\right)$e, assim como as partículas alfa, ao interagir com a matéria, perdem energia e produzem ionização. São muito mais penetrantes que as partículas alfa.

O decaimento radioativo por emissão de partículas $\beta^{-}$é um processo no qual o nêutron é transformado em um próton e um elétron (CHERRY, 2003). A Figura 4 representa o decaimento $\beta^{-}$.

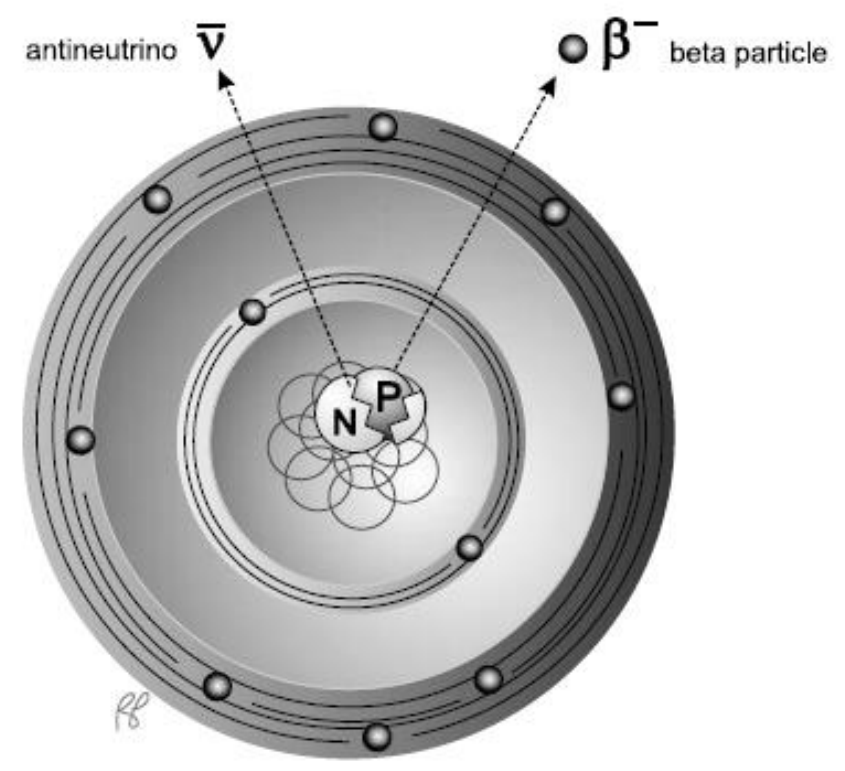

Figura 4 - Decaimento $\beta^{-}$.

Fonte: Powsner (2006).

Esse processo pode ser representado esquematicamente por:

$$
n \rightarrow p^{+}+e^{-}+v+\text { energia }
$$

O elétron é a partícula $\beta^{-}$e o neutrino (v) é uma partícula eletricamente neutra (RUSSEL, 1994).

Esse tipo de radiação, praticamente, não sofre interação com a matéria e o decaimento pode ser representado com a notação: 


$$
{ }_{Z}^{A} X \stackrel{\beta^{-}}{\longrightarrow}{ }_{Z+1}^{A} Y
$$

No decaimento radioativo por emissão de partícula $\beta^{+}$um próton do núcleo é transformado em um nêutron e um pósitron. A Figura 5 mostra o decaimento $\beta^{+}$.

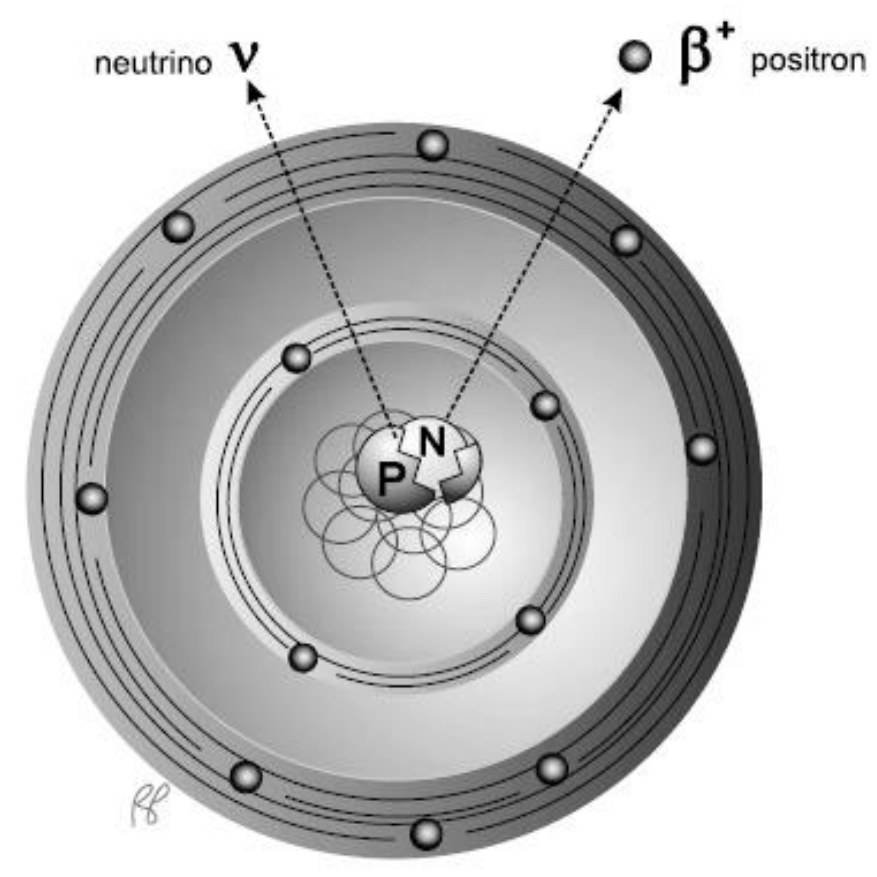

Figura 5 - Decaimento $\beta^{+}$.

Fonte: Powsner (2006).

Esse processo pode ser mostrado esquematicamente por:

$$
p^{+} \rightarrow n+e^{+}+v+\text { energia }
$$

A notação para o decaimento $\beta^{+}$é dada por:

$$
{ }_{Z}^{A} X \stackrel{\beta^{+}}{\longrightarrow}{ }_{Z-1}^{A} Y
$$

No decaimento $\beta^{+}$um pósitron é ejetado do núcleo ocorrendo uma redução no número atômico do átomo "filho" (CHERRY, 2003). Quando uma partícula $\beta^{+}$interage com um elétron do meio, ocorre uma interação de aniquilação entre as partículas. Dois fótons são emitidos na mesma direção, mas sentidos opostos e cada um possui energia de 0,511 MeV (POWSNER, 2006). A Figura 8 mostra uma reação de aniquilação. 


\section{Decaimento Gama e Raios X}

O decaimento gama produz ondas eletromagnéticas extremamente penetrantes que podem ser blindadas com chumbo, concreto, terra ou aço. Em uma única interação, um fóton de radiação gama pode perder, praticamente, toda energia e a distância percorrida antes da interação não pode ser prevista (OKUNO, 1982).

A radiação gama, analogamente aos raios $\mathrm{X}$ é uma onda eletromagnética produzida pela transição de um estado excitado para um estado de menor excitação. No entanto, a radiação gama é originada no núcleo, enquanto os raios $\mathrm{X}$ são originados fora do núcleo por um processo de desaceleração dos elétrons (GARCIA, 2002).

A emissão de radiação gama apenas libera o excesso de energia, podendo ser emitida após a emissão alfa ou beta, visto que a instabilidade do núcleo está associada à proporção entre número de prótons e nêutrons. Em algumas reações nucleares pode acontecer a formação de estados excitados de um nuclídeo ocorrendo, então, a emissão de raios gama (GARCIA, 2002).

\subsection{INTERAÇÃO DA RADIAÇÃO COM A MATÉRIA}

Como o foco deste trabalho está voltado para o uso de radiação eletromagnética para diagnóstico na medicina nuclear, trataremos, apenas, de radionuclídeos emissores de radiação eletromagnética.

A interação dos raios gama e dos raios $\mathrm{X}$ com a matéria pode ocorrer por efeito fotoelétrico, espalhamento Compton ou formação de pares (EISBERG, 1979).

\subsubsection{Efeito Fotoelétrico}

O efeito fotoelétrico (Figura 6) ocorre quando um fóton interage com um elétron orbital transferindo para ele toda a sua energia. Nessa interação o fóton desaparece e o átomo é ionizado (POWSNER, 2006).

Para ocorrer efeito fotoelétrico, o fóton incidente deve possuir energia suficiente para romper a atração eletrostática que o núcleo exerce sobre o elétron e fornecer quantidade de movimento suficiente para que a partícula abandone o átomo. Quanto mais interno o 
elétron, maior deverá ser a energia necessária para arrancá-lo do seu orbital (GARCIA, 2002).

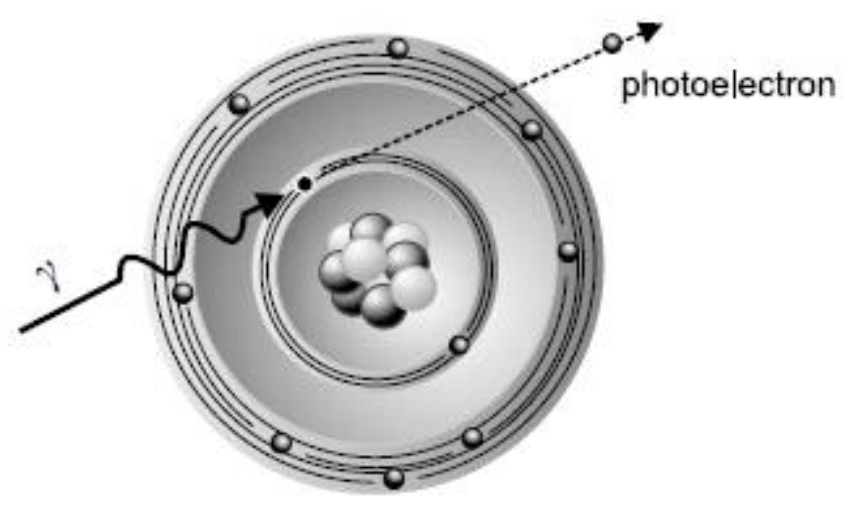

Figura 6 - Efeito Fotoelétrico.

Fonte: Powsner (2006).

\subsubsection{Espalhamento Compton}

Na interação Compton (Figura 7), os raios $\mathrm{X}$ transferem para os átomos-alvo parte da sua energia, a fim de promover o deslocamento de elétrons que estão situados principalmente nos orbitais mais periféricos da eletrosfera (GARCIA, 2002).

A energia não transferida deixa o átomo como um fóton emergente (POWSNER, 2006).

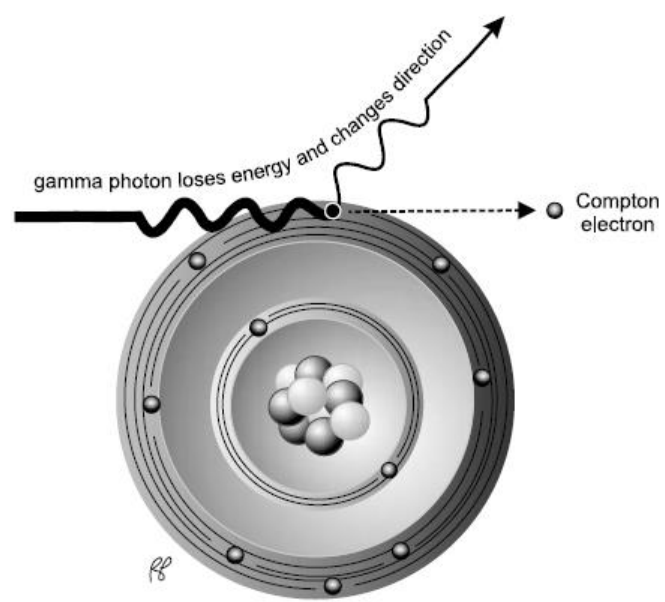

Figura 7 - Espalhamento Compton.

Fonte: Powsner (2006). 


\subsubsection{Produção de Pares}

$\mathrm{Na}$ produção de par, um fóton de alta energia, ao se aproximar de um núcleo atômico pesado, é transformado em duas partículas com massas semelhantes à massa do elétron. $\mathrm{O}$ pósitron e o elétron afastam-se com grande velocidade (GARCIA, 2002). A Figura 8 mostra fótons de aniquilação (originados da aniquilação de pares partícula-antipartícula).

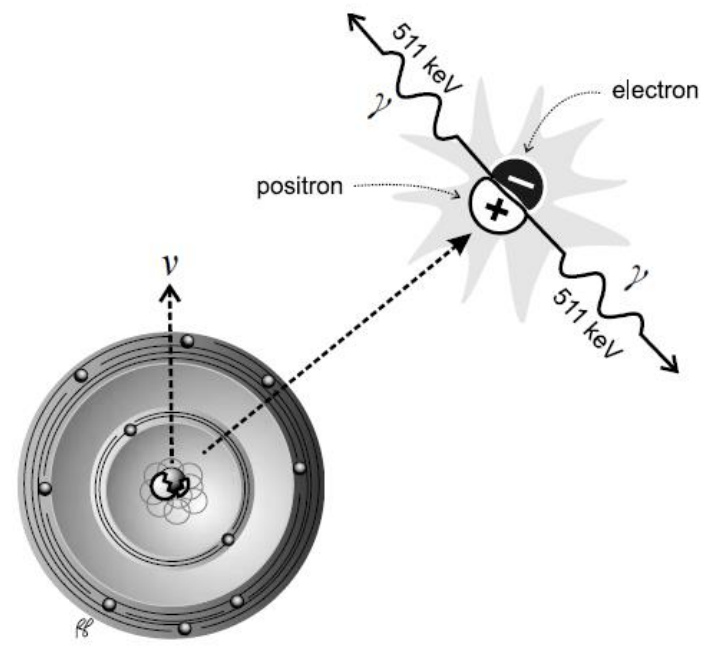

Figura 8 - Reação de Aniquilação.

Fonte: Powsner (2006)

\subsection{EFEITOS BIOLÓGICOS DAS RADIAÇÕES}

Ainda nos primeiros experimentos sobre os raios X, Emil H. Grubbé desenvolveu um quadro clínico de radiolesões ao desenvolver um processo de dermatite aguda nas mãos devido à exposição prolongada à radiação. Becquerel também apresentou um quadro de radiolesão após transportar uma amostra radioativa no bolso do colete. Houve, também, um caso de câncer radioinduzido que foi diagnosticado em 1902. Tratava-se de um dos fabricantes de tubos de raios X (OKUNO, 1988).

Esses casos revelaram que a ação da radiação no organismo trazia consequências negativas posteriores, tais como queimaduras, dermatites entre outras sequelas. Estes são apenas alguns dos diversos prejuízos causados pela exposição à radiação, sendo que a gravidade destas radiolesões está associada a fatores que vão desde o tipo de radiação, dose absorvida, energia até os tipos de tecidos e órgãos atingidos (TILLY, 2010).

A escala de risco de exposição à radiação pode ser computada a partir da interação da radiação com o meio celular (KARP, 2005). Este processo pode ocorrer por ação direta ou 
por ação indireta. $\mathrm{Na}$ ação direta, a radiação age diretamente sobre o DNA provocando determinadas alterações, enquanto que na ação indireta a radiação interage com uma molécula de água, produzindo um radical hidroxila que, por sua vez, provoca uma alteração no DNA. O que acontece é que a energia liberada com a passagem da radiação pode causar excitação dos átomos ocasionando a formação de íons e radicais livres muito reativos. Esta cadeia de eventos impede o funcionamento natural do DNA, a célula continua vivendo, no entanto, torna-se incapaz de dividir-se prejudicando, assim, o funcionamento de órgãos e tecidos (GARCIA, 2002).

Esses efeitos, provocados pela ação da radiação, podem se manifestar a curto e a longo prazo. Os efeitos a curto prazo ou agudos são observados em apenas horas, dias ou semanas após a exposição do individuo. Estão associados a altas doses de radiação e podem causar náuseas, vômitos, prostração, perda de apetite e peso, febre, hemorragias dispersas, queda de cabelo, entre outros sintomas. Outro fato que deve ser levado em consideração é a sensibilidade dos seres vivos às radiações que pode variar de indivíduo para indivíduo (OKUNO, 1982).

Nos efeitos a longo prazo ou tardios a célula é danificada, porém sobrevive e se reproduz. Os efeitos tardios são classificados em efeitos genéticos e/ou efeitos somáticos (GARCIA, 2002).

Os efeitos genéticos afetam os descendentes da pessoa irradiada. Geralmente são originados de pequenas doses crônicas em um longo intervalo de tempo. Quando a radiação afeta as células reprodutoras do indivíduo, pode acontecer que seus descendentes sejam afetados. Algumas mutações são letais antes do nascimento do feto, outras produzem distúrbios físicos e mentais, sendo que a informação genética alterada pode passar de uma geração para outra (OKUNO, 1988).

Os efeitos somáticos afetam diretamente a pessoa exposta à radiação, não são transmitidos a gerações futuras e as consequências dependem do tipo de radiação, qual órgão ou tecido foi afetado, quanto tempo que o indivíduo foi irradiado e qual foi a dose absorvida (GARCIA, 2002). 


\subsection{CONCEITOS DE DOSIMETRIA}

Tendo conhecido os efeitos biológicos causados pela exposição à radiação, é de extrema importância estudar medidas que visem reduzir essa exposição, buscando um equilíbrio entre a menor dose de radiação e a qualidade, seja do diagnóstico ou do tratamento. Para isso, são necessárias grandezas dosimétricas que visem definir valores para exposição externa (quando a fonte emissora de radiação está localizada fora do corpo) e para exposição interna (quando a fonte emissora de radiação está localizada dentro do corpo, via injeção, ingestão ou inalação).

\subsubsection{Dosimetria Externa}

Quando um corpo absorve certa quantidade de energia da radiação, essa quantidade de energia absorvida pelos tecidos ou órgãos é chamada dose absorvida. A grandeza dose absorvida $(D)$ é estabelecida por:

$$
D=\frac{E}{m}
$$

em que $E$ é a energia absorvida da radiação e $m$ é a massa do absorvedor. A unidade de medida no Sistema Internacional de Unidades é o Gray $(G y)$.

Além da quantidade de radiação absorvida leva-se em consideração o tipo de radiação que será absorvida. Essa grandeza é chamada dose equivalente $(H)$ e é definida por:

$$
H=D \cdot Q \cdot N
$$

em que $D$ é a dose absorvida, $Q$ é o fator de qualidade que considera a capacidade de ionização de cada tipo de radiação e $N$ é a capacidade de ionização com o meio. A unidade de medida da dose equivalente, no Sistema Internacional, é o Sievert (Sv) (TILLY, 2010).

\subsubsection{Dosimetria Interna}

Para quantificar a energia ionizante absorvida devido a uma exposição interna é necessário definir algumas grandezas dosimétricas. Não há como medir a dose do material radioativo que entra no corpo e, por isso, esta dose deve ser calculada por meio de modelos matemáticos (OKUNO, 2010). 
A taxa de dose absorvida em um órgão pode ser calculada como:

$$
D=\frac{A \sum_{i} y_{i} E_{i} \Phi_{i}}{m}
$$

em que $A$ é a Atividade incorporada, $y_{i}$ é o número de partículas emitidas, $E_{i}$ é a energia por desintegração das partículas emitidas, $\Phi_{i}$ é a fração de energia emitida e $m$ é a massa do órgão.

A Dose Absorvida Acumulada pode ser calculada como:

$$
\begin{gathered}
d D=D_{0} e^{-\lambda_{e f} t} d t \\
D=D_{0} \int_{0}^{\tau} e^{-\lambda_{e f} t} d t \\
D=\frac{D_{0}}{\lambda_{\text {eff }}}\left(1-e^{-\lambda_{\text {ef }} \tau}\right)
\end{gathered}
$$

Para um tempo longo $(t \rightarrow \infty)$, quando todos radionuclídeos se desintegrarem, temse:

$$
D=\frac{D_{0}}{\lambda_{\text {ef }}}=\frac{A_{0} \sum_{i} y_{i} E_{i} \Phi_{i}}{\lambda_{e f} m}
$$

em que $A_{0}$ é a atividade incorporada no instante $t=0$. Se o radionuclídeo emitir somente um tipo de partícula e a energia emitida for totalmente absorvida pelo órgão, então:

$$
D=\frac{A_{0} E}{\lambda_{e f} m}
$$

\subsection{PROTEÇÃO RADIOLÓGICA}

As grandezas Dose Absorvida e Dose Equivalente são definidas por órgãos competentes como ICRP (International Commission on Radiological Protection), ICRU (International Commission on Radiation Units and Measurements) e, no Brasil, a CNEN (Comisssão Nacional de Energia Nuclear). Estas instituições, visando designar meios de proteção radiológica, estabelecem limites máximos permissíveis de dose de radiação, com o objetivo de limitar os efeitos nos indivíduos expostos. 
Tabela 1: Limites de Doses Anuais (mSv) estabelecidos pela norma CNEN NE 3.01 (2011).

\begin{tabular}{lcc}
\hline \multicolumn{1}{c}{ Grandezas } & Trabalhador & Público \\
\hline Dose Equivalente Efetiva para o corpo inteiro & ${ }^{*} 20$ & ${ }^{* *} 1$ \\
Dose Equivalente para o cristalino & ${ }^{*} 20$ & 15 \\
Dose Equivalente para pele & 500 & 50 \\
Dose Equivalente para mãos e pés & 500 & - \\
\hline
\end{tabular}

Fonte: Diretrizes Básicas de Proteção Radiológica - CNEN (2011)

Para os que trabalham com radiação, o limite anual de dose equivalente é recomendado pela CNEN e pela ICRP como sendo $20 \mathrm{mSv}$. Para indivíduos do público o limite máximo permissível de dose anual é de $1 \mathrm{mSv}$. Estas precauções, estabelecidas pelos órgãos citados, servem para limitar riscos e prevenir acidentes oriundos da exposição à radiação (OKUNO, 1982).

\subsection{MEDICINA NUCLEAR}

A descoberta da radioatividade despertou interesse pelos danos que causavam às estruturas vivas e, posteriormente, pelos benefícios decorrentes do diagnóstico e tratamentos de várias doenças. Na medicina nuclear, por exemplo, utilizam-se os radiofármacos (compostos marcados com partículas radioativas) para estas finalidades.

No tratamento de determinadas doenças, principalmente na área oncológica, o uso das radiações ionizantes revela-se eficaz compensando os diversos efeitos colaterais que ocasionalmente se manifestam (FURNARI, 2009). No diagnóstico, a aplicação dos radioisótopos tem como objetivo detectar e verificar a extensão da patologia (OLIVEIRA, 2006).

Estas aplicações permitem o uso da radioatividade tanto para erradicar doenças quanto para o diagnóstico sem a necessidade de procedimentos clínicos invasivos e visam propiciar uma melhor qualidade de vida aos pacientes. Sendo assim, será feita uma abordagem teórica sobre as aplicações da radioatividade na medicina nuclear, bem como um breve estudo sobre preparações radiofarmacêuticas e seu uso em técnicas de

\footnotetext{
* Média aritmética em 5 anos consecutivos, desde que não exceda 50 mSv em qualquer ano.

** Em circunstâncias especiais, a CNEN poderá autorizar um valor de dose efetiva de até $5 \mathrm{mSv}$ em um ano, desde que a dose efetiva média em um período de 5 anos consecutivos, não exceda a $1 \mathrm{mSv}$ por ano.
} 
diagnóstico por imagem com o objetivo de entender melhor a dosagem de radionuclídeos em organismos vivos (FURNARI, 2009).

\subsubsection{Tratamento}

Nos primórdios do século XIX nada era sabido sobre os possíveis efeitos das radiações, mas já se percebia que as radiações destruíam tecidos vivos e por isso poderia ser utilizada na terapia de várias lesões.

O uso da radioatividade no tratamento de doenças era feito de forma empírica, isto é, não baseavam sua aplicação em estudos científicos e sim na experiência que tinham sobre os efeitos danosos das radiações. As pessoas que se submetiam a estes tratamentos eram expostas a doses altíssimas, já que a terapia acontecia coletivamente. Os pacientes sentavam em uma sala segurando uma fonte de rádio sobre suas lesões por um tempo definido sem nenhum critério. Nesse período ocorreram consequências terríveis que alertaram médicos e pacientes sobre as doses de radiação e o tempo de exposição ao qual eram submetidos (OLIVEIRA, 2006).

Atualmente, a radioterapia é a mais usada no tratamento do câncer. Frequentemente, pode ser associada com a quimioterapia e outros recursos usados no tratamento de tumores (MACHADO, 2011). Essa modalidade de tratamento, através do poder de ionização das radiações, altera a capacidade reprodutiva das células cancerígenas. Porém, há algumas limitações clínicas, principalmente relacionadas aos danos nos tecidos normais e os possíveis efeitos colaterais, como náuseas e vômitos, que afetam o estado nutricional do paciente. Outros efeitos ainda podem ser mencionados como o cansaço e reação da pele, como vermelhidão, irritação, queimaduras e ressecamento (PAIXÃO, 2010).

O resultado da radioterapia quase sempre é eficaz (LIMA, 2011). Mesmo quando não se obtém a cura completa do tumor, há uma diminuição do tamanho do mesmo, aliviando a pressão, dores e reduzindo hemorragias, o que proporciona uma melhor qualidade de vida ao paciente (SCAFF, 1997).

\subsubsection{Diagnóstico}

Já na primeira década após a descoberta dos raios X, por Röntgen, os médicos começaram a usar as radiações para realizar exames no corpo humano. Os primeiros diagnósticos, com o uso da radiografia, foram para identificar fraturas de ossos (FURNARI, 2009). 
A prática médica que envolve o uso de radiações para diagnóstico de várias doenças permanece se desenvolvendo num contexto de extrema importância. Na medicina nuclear, a administração de pequenas quantidades de compostos radioativos associados a um fármaco (radiofármacos) permite fornecer informações sobre a gravidade e características gerais da doença.

Para se realizar o diagnóstico em medicina nuclear, utilizam-se radiofármacos que tem em sua composição radionuclídeos emissores de radiação gama $(\gamma)$ ou emissores de pósitrons $\left(\beta^{+}\right)$. Os radiofármacos são introduzidos no corpo do paciente e atingem os tecidos, órgãos ou sistema que se deseja analisar. Ao atingirem o local específico, emitem radiações que são detectadas fora do organismo formando, então, as imagens que permitem o diagnóstico de várias doenças.

Diferentemente de outros métodos invasivos, para o procedimento de diagnóstico em medicina nuclear são utilizados dois tipos tomográficos o SPECT (Single-Photon Emission Computerized Tomography) e o PET (Positron Emission Tomography). Para estes tipos de exames, intenta-se que o radionuclídeo tenha tempo de meia-vida suficientemente curto para minimizar a exposição do paciente à radiação e suficientemente longo para adquirir e processar as imagens com definição (OLIVEIRA, 2006).

\subsubsection{Preparações Radiofarmacêuticas}

Os radiofármacos são compostos radioativos que não possuem ação farmacológica e contém em sua composição um radionuclídeo. Estes radiofármacos são utilizados na medicina nuclear como meio de diagnóstico e tratamento de doenças.

Para fins de diagnóstico são utilizados radiofármacos que contém radionuclídeos cujo decaimento dá origem a radiação eletromagnética, visto que esta é mais penetrante possuindo, assim, capacidade de atravessar órgãos e tecidos. Geralmente, estes radiofármacos são emissores de radiação gama $(\gamma)$ ou emissores de pósitrons $\left(\beta^{+}\right)$.

Como meio de tratamento, são utilizados radiofármacos cujo decaimento do radionuclídeo presente em sua composição, dá origem a radiação ionizante. Devido à sua capacidade de ionização, esta radiação é capaz de destruir, seletivamente, as células desejadas. Para terapia, são usados radionuclídeos emissores de partículas $\alpha, \beta^{+}, \beta^{-}$ou elétrons Auger. 
Nas décadas de 1920 e 1930 foram realizadas algumas das primeiras aplicações da radioatividade na medicina. Algumas pesquisas fizeram uso de radionuclídeos naturais, no entanto, a maior parte deles possui tempo de meia vida muito longo e/ou representam elementos muito pesados, como o urânio (U) e o rádio (Ra).

Os radionuclídeos utilizados na medicina nuclear moderna são produzidos artificialmente através do bombardeamento do núcleo de átomos estáveis com partículas subnucleares (como prótons e nêutrons), ocorrendo reações nucleares que convertem um núcleo estável em um núcleo instável.

Nosso interesse neste tópico é conhecer alguns métodos usados para produção de radionuclídeos com aplicação na medicina nuclear, bem como considerar condições biologicamente relevantes para preparações radiofarmacêuticas.

Os radiofármacos para aplicações clínicas consistem na combinação de um marcador radioativo e uma molécula biologicamente ativa responsável pela biodistribuição e afinidade química com o tecido ou órgão que se deseja examinar. Para alguns agentes os próprios átomos radioativos possuem propriedades desejadas para localização, podendo ser dispensado qualquer componente químico para ligação.

Algumas características são consideradas como desejáveis em um radiofármaco. Para o marcador radioativo o fóton gama deve possuir energia e quantidade adequadas para ser detectado fora do organismo. Para as gama-câmaras utilizadas na técnica SPECT, energias entre 100 e $200 \mathrm{KeV}$ são ideais. Além da energia suficiente, o radionuclídeo deve possuir meia-vida efetiva suficientemente longa para a aplicação desejada, mas curta o bastante para diminuir sua ação no organismo.

O tecnécio-99m $\left({ }^{99 \mathrm{~m}} \mathrm{Tc}\right)$ é o radionuclídeo mais utilizado na medicina nuclear por possuir, praticamente, todos estes requisitos e por ser produzido em gerador de baixo custo (OLIVEIRA, 2006).

\subsubsection{Produção de Radionuclídeos}

Atualmente, os radionuclídeos utilizados em medicina nuclear são produzidos em reatores nucleares ou aceleradores de partículas. Os radionuclídeos que sofrem decaimento por emissão de partículas $\beta^{-}$geralmente são produzidos em reatores por reação de fissão 
nuclear ou por reações de captura de nêutrons. Os radionuclídeos que sofrem decaimento por pósitrons ou por captura eletrônica são produzidos em cíclotrons.

O sistema de gerador de radionuclídeo consiste em obter um radionuclídeo "filho" de meia-vida curta a partir de um radionuclídeo "pai" de meia-vida longa. O gerador ${ }^{99} \mathrm{Mo} /{ }^{99 \mathrm{~m}} \mathrm{Tc}$ é o mais importante para a prática clínica (OLIVEIRA, 2006).

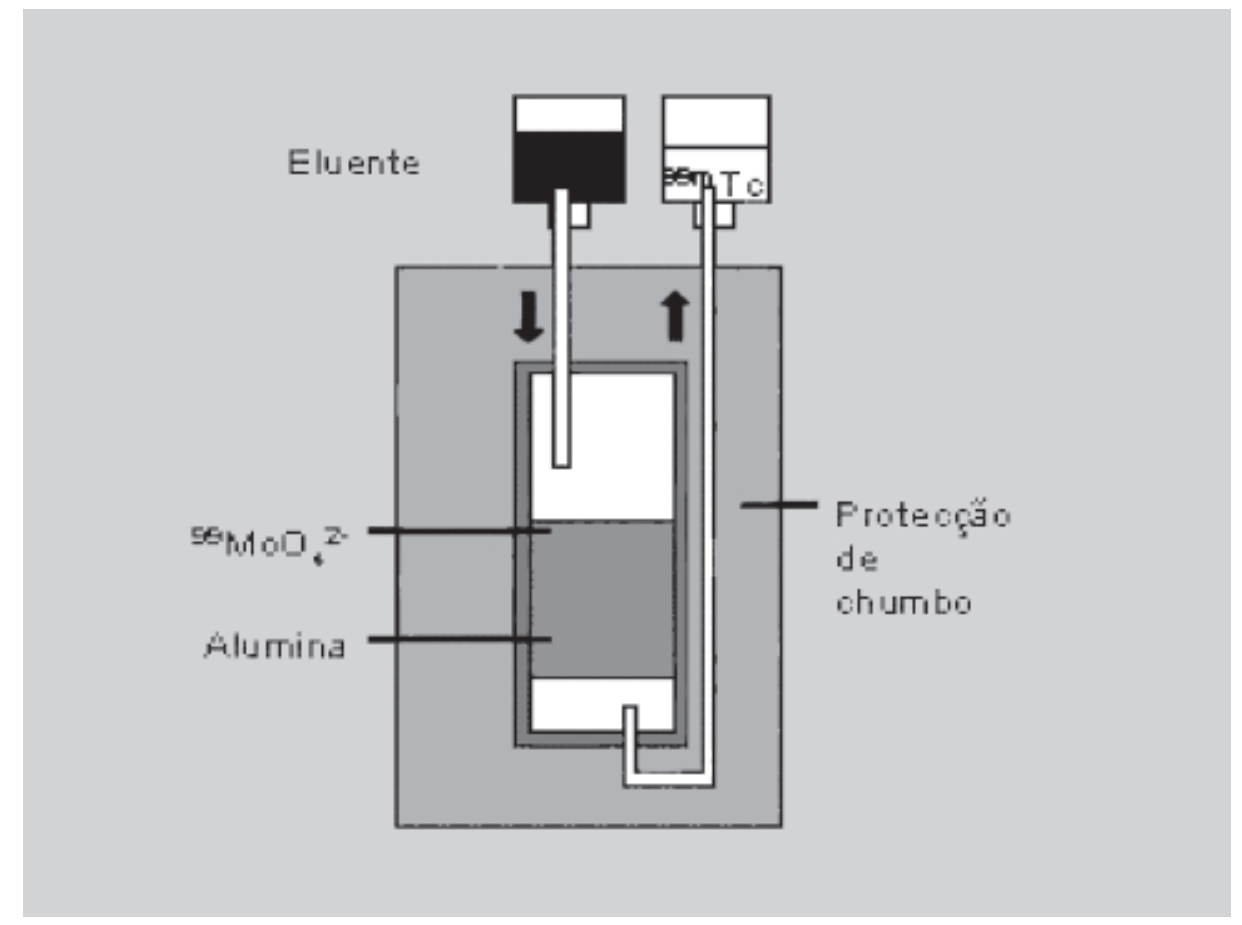

Figura 9 - Gerador ${ }^{99} \mathrm{Mo} /{ }^{99 m} \mathrm{Tc}$. O gerador é constituído por uma coluna de Alumina na qual está adsorvido o radionuclídeo "pai” ( ${ }^{99} \mathrm{Mo}$ ) na forma química de $\mathrm{MoO}_{4}^{2-}$. Por eluição com soro fisiológico é apenas eluído o ${ }^{99 m} \mathrm{TcO}_{4}^{-}$, recolhido sob vácuo, enquanto o molibdato fica retido na coluna.

Fonte: Oliveira (2006).

A escolha do radionuclídeo para aplicação clínica é baseada em suas características físicas. Em diagnóstico é importante que o radiofármaco seja captado seletivamente pelo órgão-alvo e seja metabolizado e excretado facilmente. Deseja-se, sobretudo, que o radiofármaco proporcione melhor qualidade da imagem e menor exposição do paciente à radiação (OLIVEIRA, 2006).

A Tabela 2 mostra as características físicas de radionuclídeos usados em diagnóstico. 
Tabela 2 - Radionuclídeos para diagnóstico

\begin{tabular}{|c|c|c|c|c|}
\hline Radionuclídeo & $\begin{array}{l}\text { Tempo de } \\
\text { meia-vida }\end{array}$ & $\begin{array}{c}\text { Modo de } \\
\text { Decaimento }\end{array}$ & $\begin{array}{c}\text { Energia Raios } \\
\quad \gamma(\mathrm{KeV})\end{array}$ & $\begin{array}{l}\text { Abundância da } \\
\text { Emissão r (\%) }\end{array}$ \\
\hline${ }^{99 m_{T}} \mathrm{Tc}$ & $6 \mathrm{~h}$ & ${ }^{*} \mathrm{TI}$ & 140 & 89 \\
\hline${ }^{131} \mid$ & $193 \mathrm{~h}$ & $\beta^{-}, \mathrm{g}$ & 364 & 81 \\
\hline${ }^{123} \mathrm{I}$ & $13 \mathrm{~h}$ & ${ }^{* *} \mathrm{CE}$ & 159 & 83 \\
\hline${ }^{67} \mathrm{Ga}$ & $78 \mathrm{~h}$ & CE & $\begin{array}{c}93,185,300 \\
394\end{array}$ & $37,20,17,5$ \\
\hline${ }^{111}$ In & $67 \mathrm{~h}$ & CE & 171,245 & 90,94 \\
\hline${ }^{201} \mathrm{Tl}$ & $73 \mathrm{~h}$ & CE & 135,167 & 3,20 \\
\hline${ }^{11} \mathrm{C}$ & $20,4 \mathrm{~min}$ & $\beta^{+}$ & 511 & 99,8 \\
\hline${ }^{13} \mathrm{~N}$ & $10 \mathrm{~min}$ & $\beta^{+}$ & 511 & 100 \\
\hline${ }^{15}$ o & $2,07 \mathrm{~min}$ & $\beta^{+}$ & 511 & 99,9 \\
\hline${ }^{18} \mathrm{~F}$ & $110 \mathrm{~min}$ & $\beta^{+}$ & 511 & 96,9 \\
\hline${ }^{124} I$ & 4,2 dias & $\beta^{+}$ & 511 & 25 \\
\hline${ }^{64} \mathrm{Cu}$ & $13 \mathrm{~h}$ & $\beta^{+}$ & 511 & 38 \\
\hline
\end{tabular}

Fonte: Preparações Radiofarmacêuticas e suas Aplicações, Revista Brasileira de Ciências Farmacêuticas (2006).

As preparações radiofarmacêuticas destinadas à prática de diagnóstico em medicina nuclear devem, necessariamente, possuir características que assegurem o paciente de receber a mínima dose de radiação possível, mantendo a qualidade do resultado esperado.

\footnotetext{
* Transição Isomérica

** Captura Eletrônica
} 
As preparações radiofarmacêuticas podem ser de vários tipos e é de fundamental importância que recebam um processo de controle de qualidade adequado (OLIVEIRA, 2006).

\subsection{MÉTODOS TOMOGRÁFICOS}

\subsubsection{SPECT}

Na década de 1950, o Dr. Harold Anger propôs o projeto básico de um aparelho conhecido como câmara de cintilação que, hoje, é utilizada no processamento de imagens da medicina nuclear. Esses aparelhos (também conhecidos como gama-câmara) são associados a computadores que fazem a coleta de dados permitindo, então, a visualização e registro das imagens (POWSNER, 2006).

A câmara de cintilação é constituída, basicamente, por um detector (constituído por um ou mais cristais de iodeto de sódio) e por um colimador de chumbo (responsável por selecionar a radiação). Diferentes tipos de colimadores podem ser utilizados nas câmarasgama e sua utilização está associada com determinadas faixas de energias com resolução e sensibilidade distintas. A Figura 10 mostra os componentes da câmara de cintilação. 


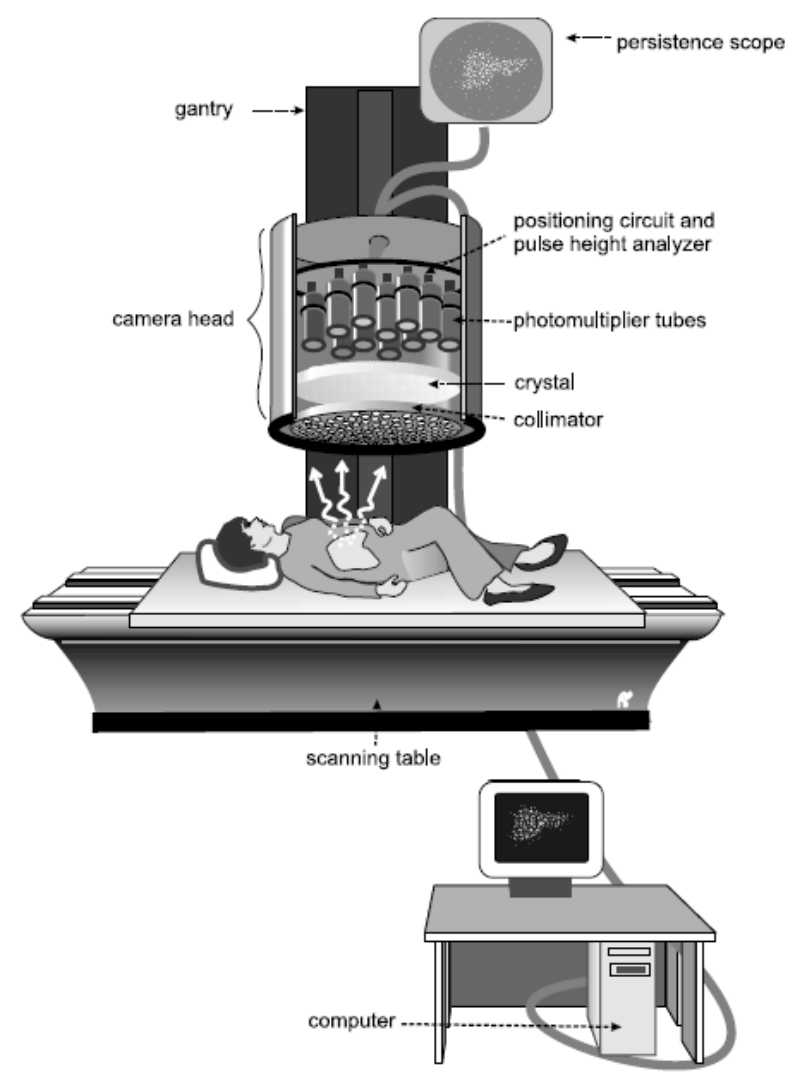

Figura 10 - Componentes da Câmara de Cintilação.

Fonte: Powsner (2006)

A técnica que envolve SPECT gera uma imagem tomográfica, que evidencia a distribuição da radiação no organismo do paciente à medida que o detector gira até $180^{\circ}$ ou $360^{\circ}$ em volta do paciente que está deitado. A técnica permite a obtenção de imagens nos diversos planos anatômicos (OLIVEIRA, 2006). A Figura 11 mostra um modelo de aparelho de SPECT.

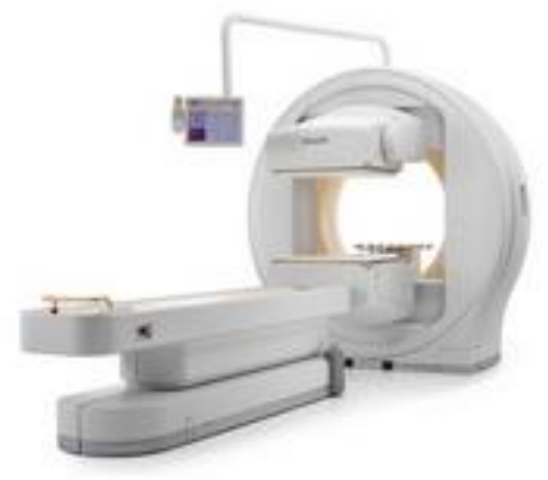

Figura 11 - BrightView SPECT.

Fonte: Philips (2010) 


\subsubsection{PET}

A técnica PET faz uso de radionuclídeos emissores de pósitrons que interagem com elétrons, emitindo dois fótons $\gamma$ (energia de $511 \mathrm{keV}$ cada um), na mesma direção, mas com sentidos opostos. Os fótons são captados externamente por um detector circular (Figura 12), que permite imagens tridimensionais.

A imagem cintilográfica gerada permite avaliar a distribuição do radiofármaco e verificar sua fixação em determinados órgãos ou tecidos (OLIVEIRA, 2006).

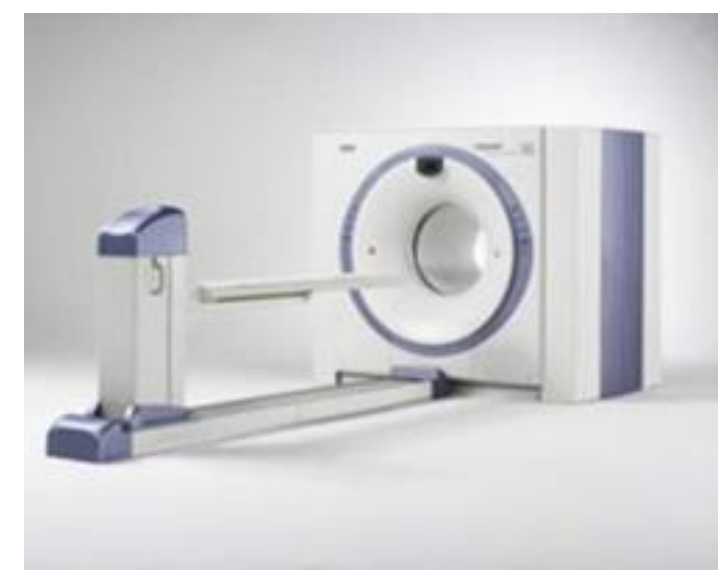

Figura 12 - Aparelho PET-CT.

Fonte: Siemens (2011).

\subsection{CONTROLE DE QUALIDADE}

O controle de qualidade nos setores de radiodiagnóstico visa estabelecer procedimentos para monitorar o desempenho do uso de radiação em técnicas de obtenção de imagens. A exposição de trabalhadores e pacientes deve ser controlada para que o benefício trazido pelo uso da radiação seja superior aos danos causados (AIEA, 1991).

Para diminuir a ocorrência de diagnósticos errôneos e garantir imagens cintilográficas precisas e verdadeiras é fundamental que o aparelho de obtenção de imagens da medicina nuclear (gama-câmara) apresente um desempenho confiável. É necessário, portanto, realizar alguns testes que obedeçam a protocolos definidos por organizações como a International Atomic Energy Agency (IAEA), a American Association of Physicists in Medicine (AAPM) e, no Brasil, a Comissão Nacional de Energia Nuclear (CNEN). Estes testes fazem parte do controle de qualidade nas câmaras de cintilação utilizadas nos setores 
de medicina nuclear e permitem, além da nitidez da imagem, o controle da dose de radiação ministrada no paciente (AAPM, 1995).

Portanto, o motivo de realizar controle de qualidade nas câmaras de cintilação é:

- Para assegurar a obtenção de imagens precisas e confiáveis em diagnósticos;

- Para corrigir problemas no equipamento antes que haja alterações nas imagens clínicas;

- Para manter o bom funcionamento do aparelho;

- Para determinar a frequência e a necessidade de calibração ou manutenção preventiva.

De acordo com a IAEA, é essencial que o controle de qualidade dos instrumentos seja considerado parte integral de um serviço de Medicina Nuclear e que seja executado por pessoas previamente treinadas.

Além do controle de qualidade nas câmaras de cintilação, é importante, ainda, realizar testes para a definição de protocolos de aquisição de imagens. Estes testes, realizados com phantoms antropomórficos, ajudam a determinar a dose de radiação administrada, além de evidenciar a importância da distância entre o detector e o paciente, bem como definir tempo de aquisição de imagem, zoom, matriz e janela energética.

\subsubsection{Uniformidade da Resposta}

O teste de Uniformidade da Resposta avalia a capacidade da câmara de produzir uma imagem uniforme quando submetida a um fluxo uniforme de fótons, ou seja, a imagem de uma fonte plana deve apresentar uma densidade de contagem constante em toda a sua extensão. Este teste deve ser realizado com o colimador de chumbo (para testar a uniformidade extrínseca) e sem o colimador de chumbo (para testar a uniformidade intrínseca) (AIEA, 1991).

\subsubsection{Linearidade na Resposta}

O teste de Linearidade visa verificar a capacidade da câmara de cintilação em determinar, com exatidão, a posição de interação do fóton dentro do cristal, ou seja, uma fonte linear 
reta deve ser reproduzida como uma linha reta na imagem (AIEA, 1991). A Figura 13 mostra um Objeto Simulador Físico sendo utilizado para realização do teste de linearidade.

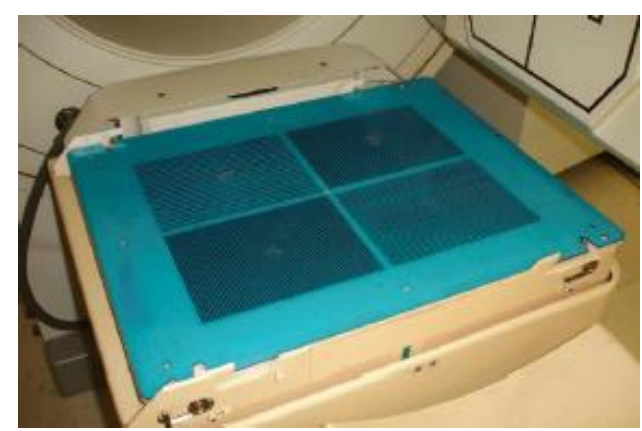

Figura 13 - Objeto Simulador Físico utilizado em testes de linearidade. Fonte: Acervo Pessoal.

A Figura 14 mostra a imagem obtida do Objeto Simulador Físico em um teste de resolução espacial e linearidade.

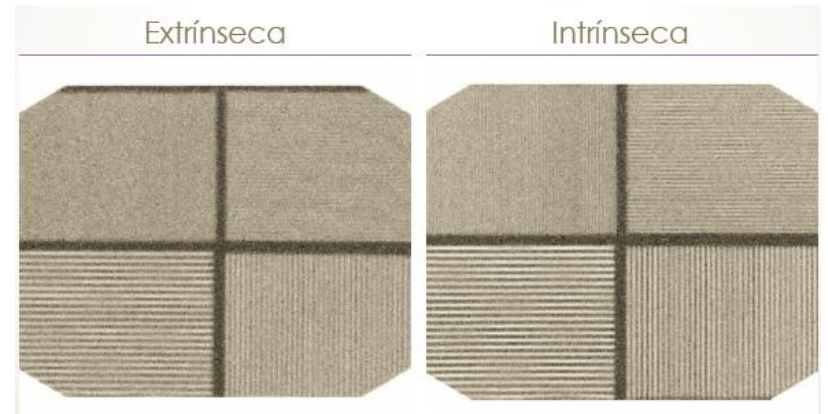

Figura 14 - Imagem obtida do Objeto Simulador Físico.

\subsubsection{Centro de Rotação}

O teste realizado para controle de qualidade do centro de rotação da câmara SPECT é, segundo a norma CNEN NN 3.05, para testar o desvio do centro de rotação do sistema. $\mathrm{O}$ termo "centro de rotação" é definido como a interseção entre o eixo de rotação à reta que passa perpendicular pelo centro do detector. 
A Figura 15 mostra uma representação do centro de rotação da câmara SPECT.

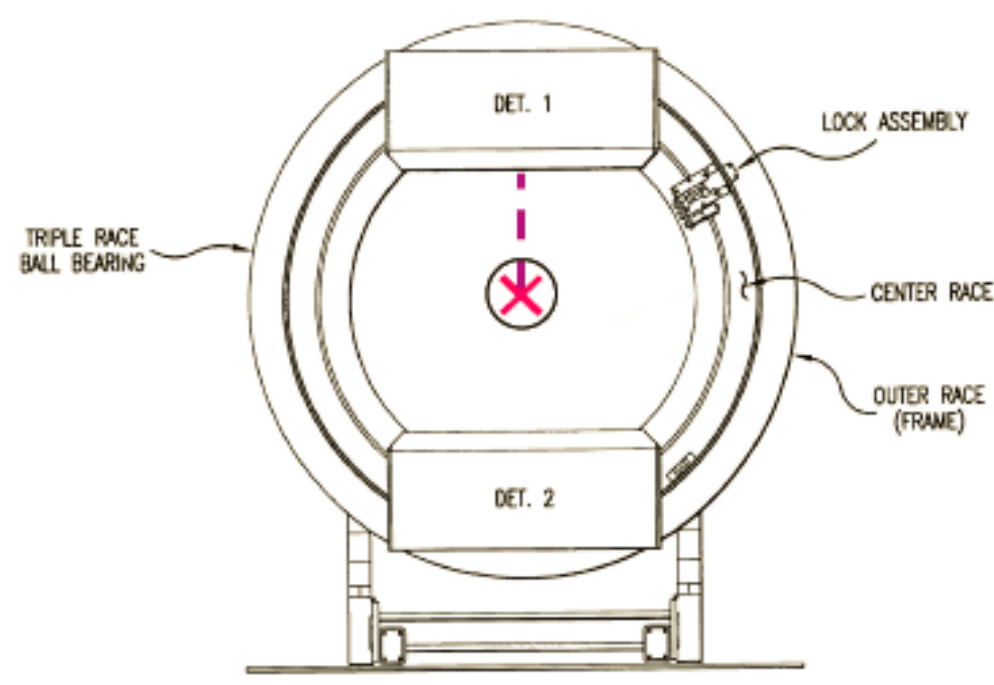

Figura 15 - Esboço da definição de centro de rotação. Fonte: Powsner (2006).

\subsubsection{Resolução Energética}

Conforme norma CENEN NN 3.05, o teste de Resolução Energética é para avaliar a capacidade da câmara cintilográfica para distinguir dois fótons de energias diferentes e próximas. Assim, a câmara cintilográfica garante a capacidade de identificar pequenas variações de energias, refletindo, assim, imagens mais seguras para diagnóstico.

\subsubsection{Sensibilidade do Sistema}

O teste de sensibilidade visa verificar a habilidade do sistema em detectar a radiação gama incidente. Geralmente, os problemas na sensibilidade podem ocorrer por várias razões, incluindo não uniformidade, variação na resolução em energia ou problemas no colimador. A sensibilidade do sistema está associada, portanto, ao conjunto: colimador, energia da fonte e distância fonte-colimador (AIEA, 1991). 


\subsection{PROTOTIPAGEM RÁPIDA}

Os primeiros métodos de prototipagem rápida surgiram no final de 1980. Ainda hoje, as técnicas de impressão 3D são utilizadas para construir um modelo físico a partir de um modelo tridimensional obtido através de dados de um computador. A impressão é realizada em finas camadas, resultando no objeto físico tridimensional desejado.

Os processos de prototipagem rápida são constituídos por cinco etapas básicas. São elas:

- Criação de um modelo CAD (Computer-aided design) da peça que está sendo projetada;

- Conversão do arquivo CAD em formato STL (estereolitografia);

- Cortes do arquivo STL em finas camadas transversais;

- Construção física do modelo, juntando-se uma camada sobre a outra;

- Limpeza e acabamento do protótipo.

Neste trabalho, a prototipagem rápida foi empregada na construção do molde utilizado para a confecção do Objeto Simulador Antropomórfico do Pâncreas.

\subsection{PÂNCREAS}

O pâncreas é uma glândula localizada sob o estômago, entre o duodeno e o baço (espaço retroperitoneal do abdômen superior). Pode ser dividido anatomicamente em quatro partes: cabeça, colo, corpo e cauda. Contem milhões de ácinos, revestidos com células glandulares secretoras, responsáveis pela secreção de enzimas digestivas no duodeno. Além se suas funções digestivas, o pâncreas secreta, ainda, dois hormônios importantes (insulina e glucagon) responsáveis pela regulação normal do metabolismo da glicose, lipídeos e proteínas. Estes hormônios são secretados diretamente no sangue pelas ilhotas de Langerhans (GUYTON, 2006). A Figura 16 mostra uma representação pictórica do Pâncreas, evidenciando as ilhotas de Langerhans e os ácinos pancreáticos. 


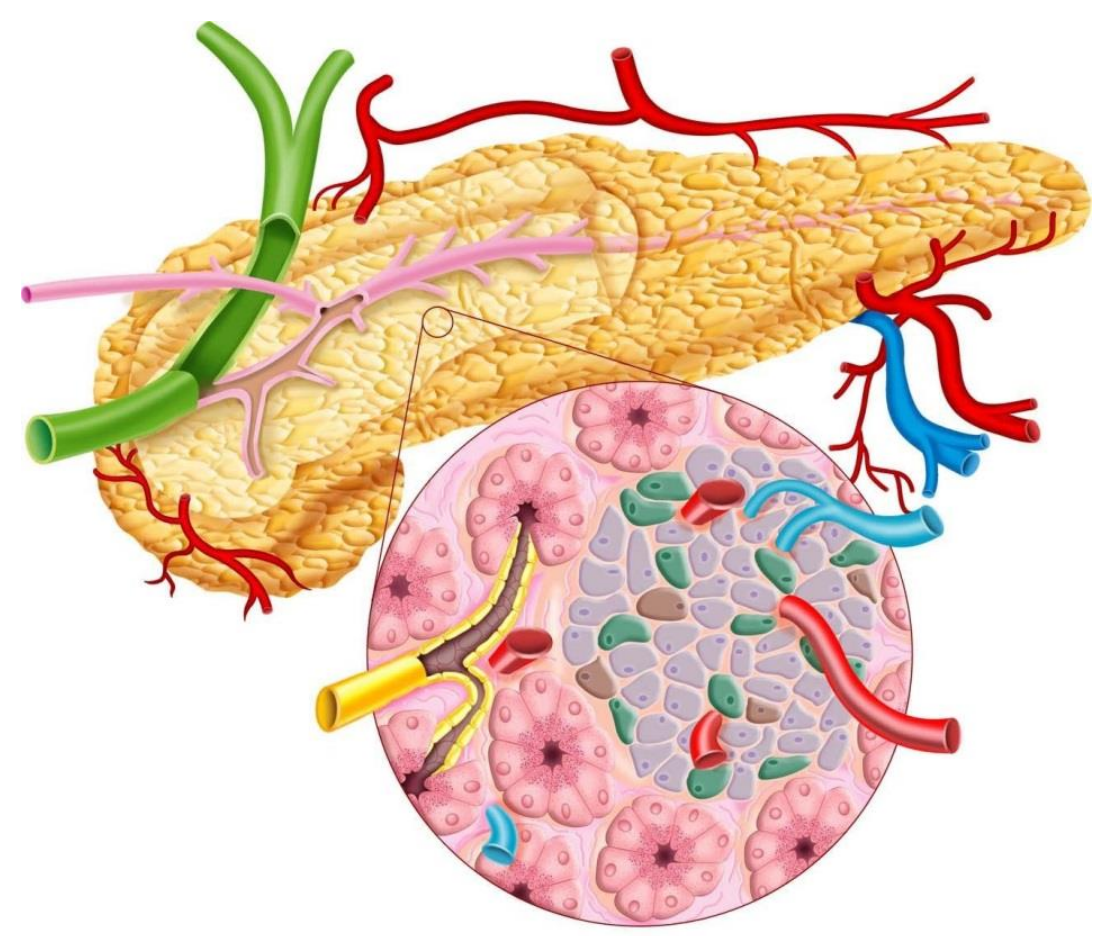

Figura 16 - Representação Pictórica do Pâncreas.

Fonte: Sheehan (2004)

O Pâncreas pode dar origem a vários processos patológicos. Atualmente, o crescente número de pessoas diagnosticadas com tumores pancreáticos revela a importância do desenvolvimento de técnicas de diagnósticos que sejam capazes de detectar, ainda em estágio inicial, qualquer patologia associada ao órgão (INCA, 2010).

A escolha do pâncreas para o desenvolvimento de um objeto simulador antropomórfico teve como instigação, além da importância do diagnóstico precoce de tumores nesta região, a importância do órgão tanto para a regulação da glicose no sangue, quanto no processo de digestão.

Entretanto, as técnicas de imagens da medicina nuclear ainda não são eficazes para diagnóstico de enfermidades pancreáticas, visto que, não foram desenvolvidos, até o momento, radiofármacos com afinidade específica para o pâncreas (MACHADO, 2002). Surge, então, a expectativa do início de prováveis estudos sobre a temática. 


\section{METODOLOGIA}

Neste trabalho, propôs-se o desenvolvimento de objetos simuladores antropomórficos do pâncreas, confeccionados com materiais de baixo custo financeiro e que possam, futuramente, estar disponíveis para diversos serviços de Medicina Nuclear do Brasil.

Para a confecção do primeiro protótipo do phantom do pâncreas foram utilizados alginato e acrílico autopolimerizável rosa (ambos de uso odontológico) para adquirir o formato do órgão. Os materiais foram preparados seguindo as instruções do fabricante. A Figura 17 mostra as proporções de água e alginato que foram utilizadas. Este material foi empregado para confecção dos moldes do Pâncreas.

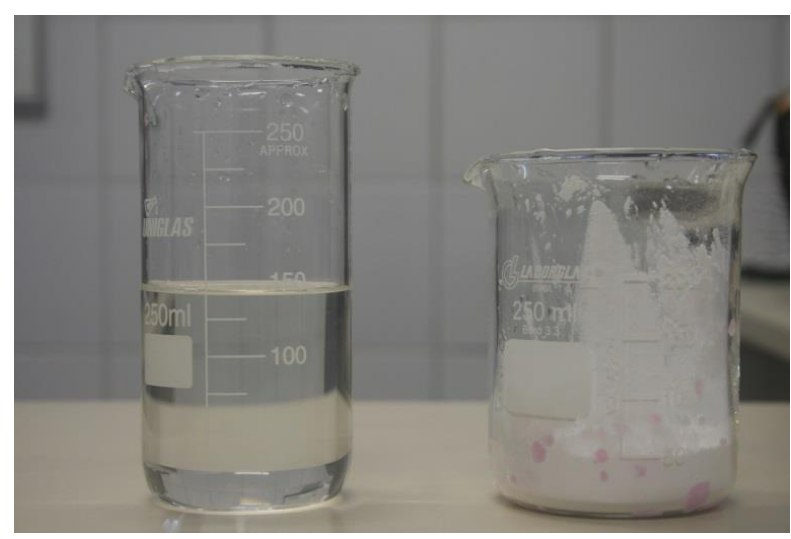

Figura 17 - Proporções utilizadas de Alginato e Água.

Fonte: Acervo Pessoal.

Em seguida, o acrílico autopolimerizável foi preparado (misturando-se o polímero e o monômero) e distribuído no molde de alginato, como mostra a Figura 18. 


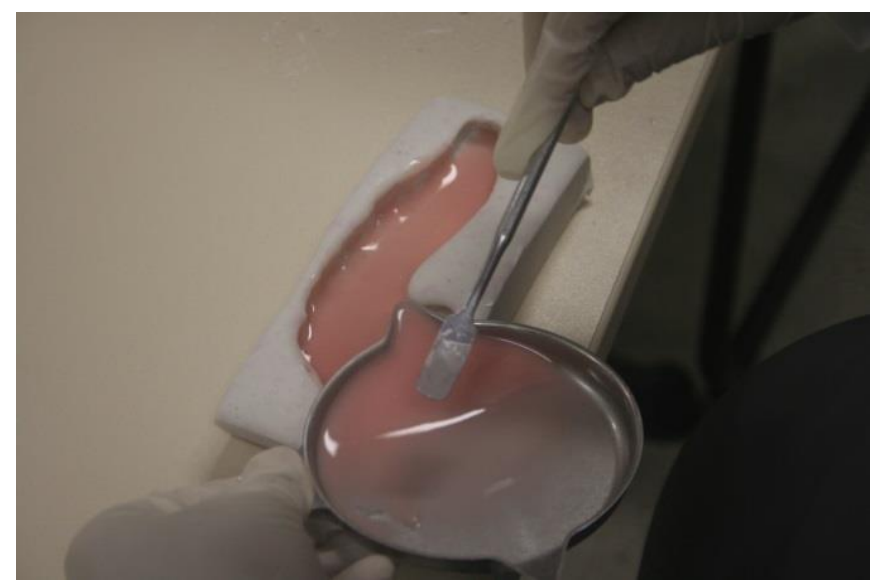

Figura 18 - Distribuição do Acrílico no Molde de Alginato.

Fonte: Acervo Pessoal.

Para os simuladores de nódulos quentes (hemangiomas), foram utilizadas bolinhas de isopor envoltas por sondas para simular a vascularização do tumor. Para a simulação dos nódulos frios (tumores não vascularizados) foi empregado o próprio acrílico autopolimerizável.

A Figura 19 mostra o primeiro protótipo do phantom do pâncreas desenvolvido na Universidade Federal do Sul e Sudeste do Pará (UNIFESSPA).

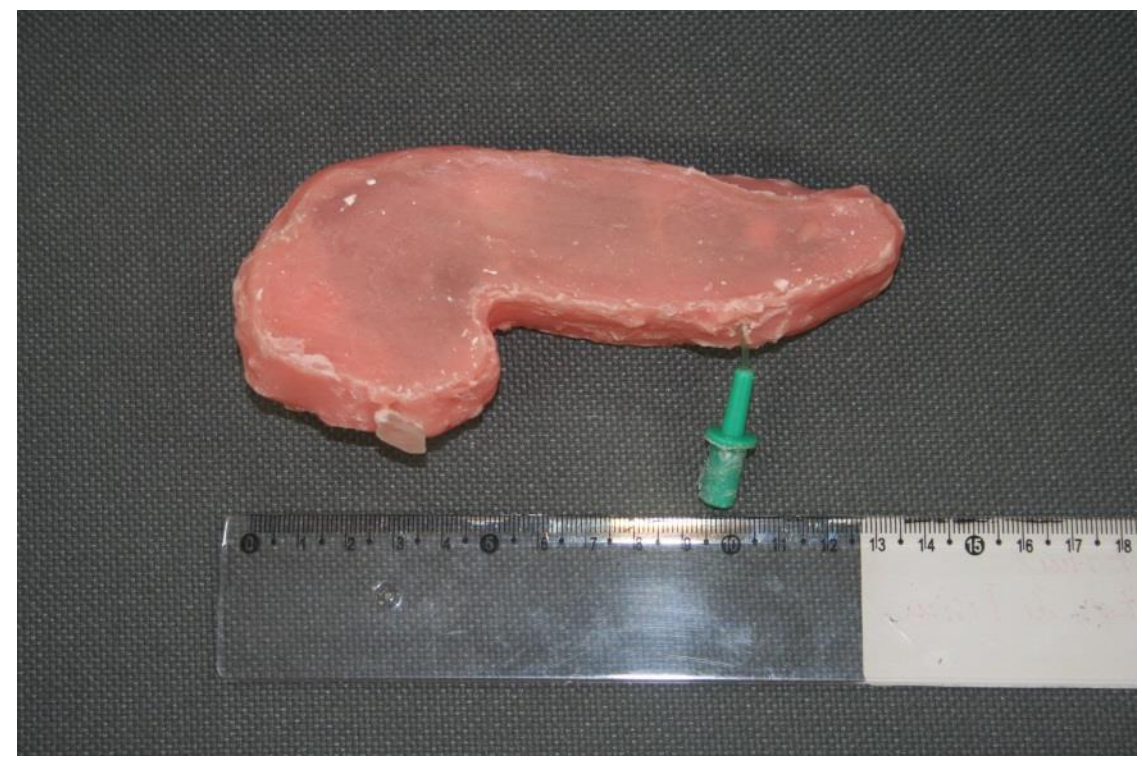

Figura 19 - Phantom do Pâncreas Desenvolvido na UNIFESSPA. Fonte: Acervo Pessoal. 
Com o intuito de aperfeiçoar a geometria do primeiro protótipo, e tendo como iniciativa o grande avanço da prototipagem rápida, técnicas de impressão 3D foram utilizadas. A Figura 20 mostra o molde impresso na impressora 3D e utilizado para confecção do segundo protótipo do objeto simulador. O molde 3D foi impresso na impressora 3D do Laboratório de Engenharia e Inovação (LEI) da Universidade de Brasília (UnB), Faculdade Gama (FGA). O material utilizado para impressão foi o plástico $\mathrm{ABS}^{2}$ (Acrilonitrila Butadieno Estireno) de cor amarela.

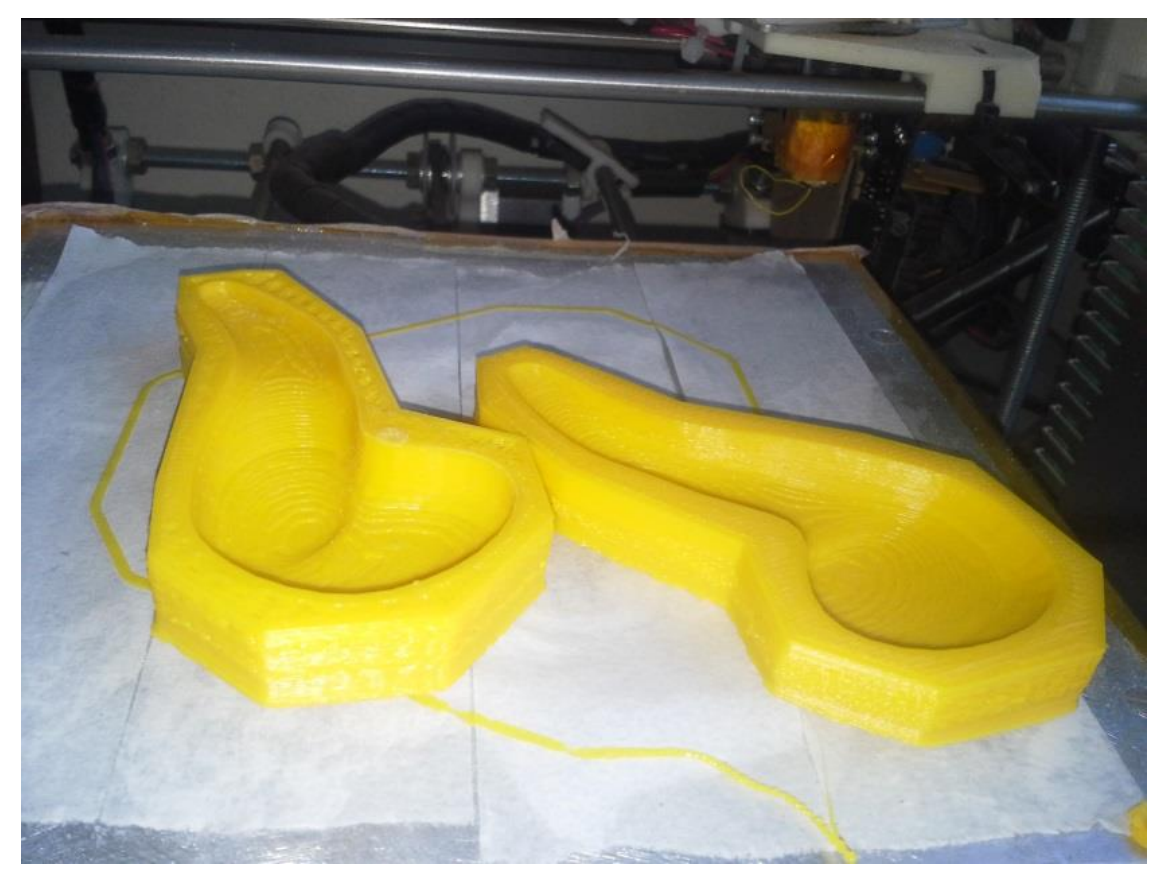

Figura 20 - Modelo do Pâncreas confeccionado na impressora 3D. Fonte: Acervo Pessoal.

Para construção do segundo protótipo do objeto simulador, o molde confeccionado na impressora 3D foi preenchido com alginato da marca Ezact Kromm. A forma adquirida com o alginato foi colocada em um recipiente também com alginato para obtenção do molde que foi preenchido com acrílico autopolimerizável da marca Jet.

\footnotetext{
${ }^{2}$ Polímero bastante rígido e leve que apresenta custo relativamente baixo.
} 
A Figura 21 apresenta o segundo protótipo confeccionado.

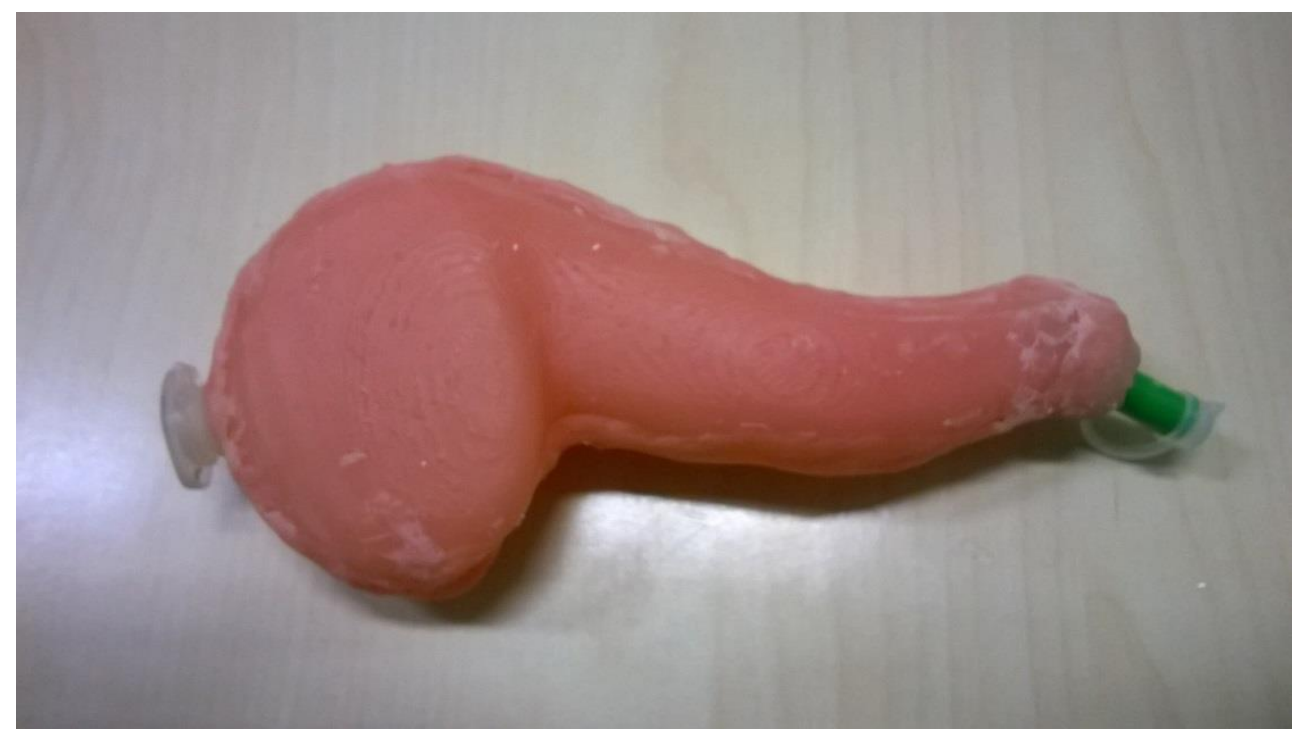

Figura 21 - Segundo protótipo do Objeto Simulador antropomórfico do Pâncreas.

Fonte: Acervo Pessoal.

\subsection{PROCEDIMENTOS PARA REALIZAÇÃO DOS TESTES}

Após a construção do primeiro protótipo do phantom do pâncreas, algumas imagens radiográficas foram realizadas na Climagem (clínica especializada em diagnóstico por imagem de Marabá, Pará). Para a realização das imagens radiográficas foi inserido, no phantom, 7,5 $\mathrm{mL}$ de contraste radiológico de ioxitalamato de meglumina da marca Telebrix diluído em solução fisiológica. $\mathrm{O}$ aparelho de raio $\mathrm{X}$ utilizado era da marca Toshiba (Rotanode). A faixa de energia que apresentou com nitidez a imagem foi de $50 \mathrm{KV}$.

Ainda com o primeiro protótipo, algumas imagens estáticas e tomográficas foram realizadas no setor de medicina nuclear do Hospital Universitário de Brasília (HUB). Para a obtenção das imagens, foi inserido no phantom Tecnécio-99m $\left({ }^{99 \mathrm{~m}} \mathrm{Tc}\right)$, com uma atividade de 1,8 mCi. Nos simuladores de hemangiomas uma pequena quantidade de ${ }^{99 \mathrm{~m}} \mathrm{Tc}$, com atividade de $2,5 \mathrm{mCi}$, também foi inserida para simular a vascularização dos tumores.

Com o segundo protótipo do objeto simulador do pâncreas, alguns testes de aquisição de imagem foram realizados no serviço de medicina nuclear do Hospital Santa Marta (Taguatinga-DF). 
Almejou-se realizar neste trabalho os seguintes testes de aquisição de imagem:

- Janela energética de 5, 10, 15 e 20\%;

- Matriz de 64x64, 128x128, 256x256 e 512x512 pixels;

- Teste de zoom 1,0, zoom 1,3, zoom 1,5, zoom 2,0.

No entanto, para garantir o bom desempenho da câmara de cintilação utilizada para obtenção das imagens, foram realizados os testes de Controle de Qualidade especificados no Capítulo 2 (uniformidade, linearidade, sensibilidade e centro de rotação) antes que as imagens do phantom fossem obtidas.

Logo após os testes de Controle de Qualidade, imagens estáticas do phantom do pâncreas foram realizadas. O tempo de aquisição destas imagens foi de 30 segundos e a matriz variou em 64 × 64, 128 × 128, 256 x 256 e 512 × 512 pixels. Para cada matriz o zoom variou em 1,$0 ; 1,3 ; 1,5$ e 2,0 .

No próximo Capítulo serão apresentados e discutidos os resultados das aquisições das imagens. 


\section{RESULTADOS E DISCUSSÕES}

Através das imagens realizadas com o primeiro protótipo do phantom do pâncreas identificou-se que o objeto simulador apresenta, na radiografia, geometria semelhante à do órgão real. A Figura 22 mostra a radiografia do primeiro protótipo do objeto simulador do pâncreas.

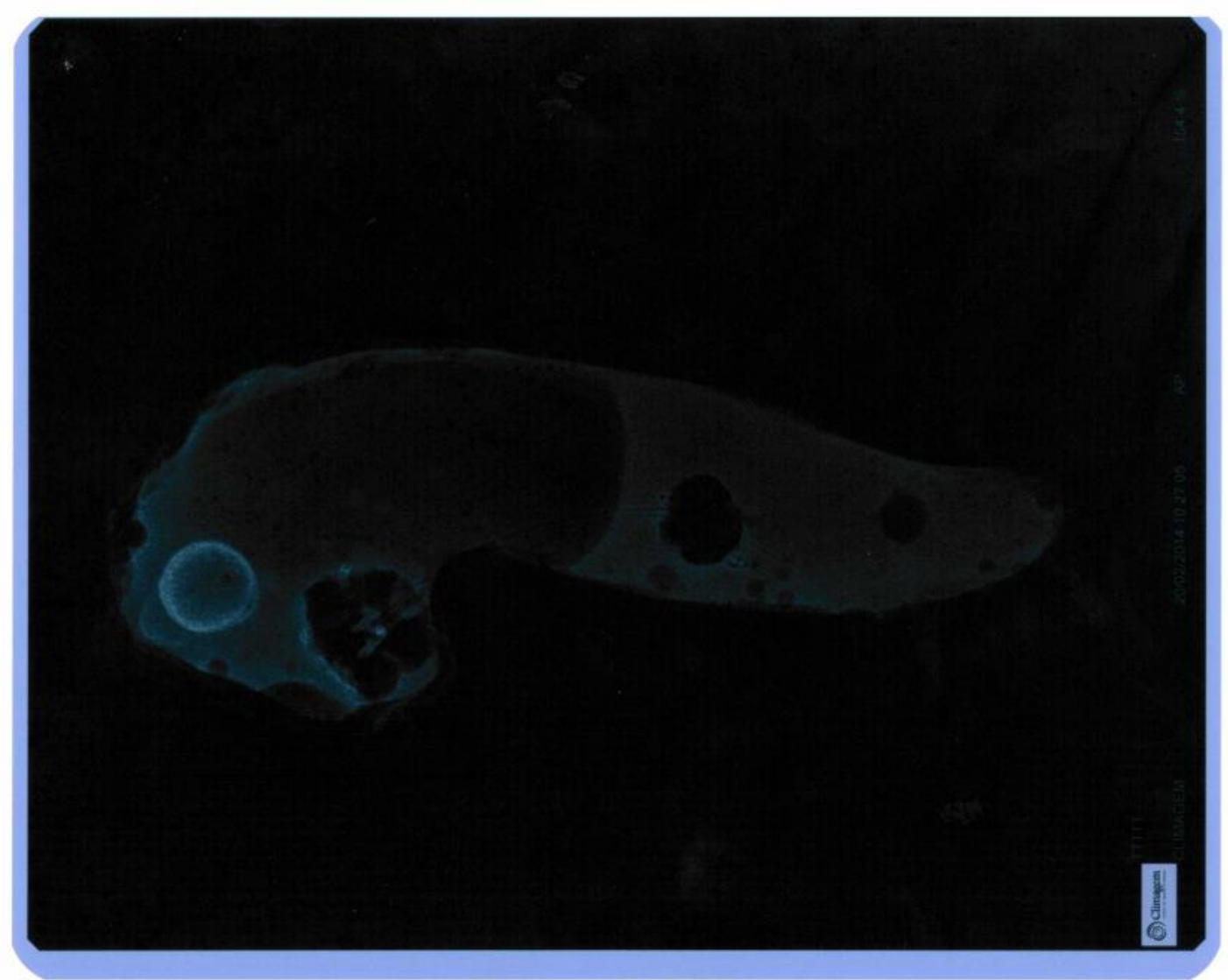

Figura 22 - Radiografia do phantom do pâncreas.

Fonte: Acervo Pessoal.

As imagens realizadas no HUB serão apresentadas a seguir. A Figura 23 ilustra as imagens estáticas (anterior/posterior) do phantom do pâncreas. A Figura 24 mostra as imagens cintilgráficas. 


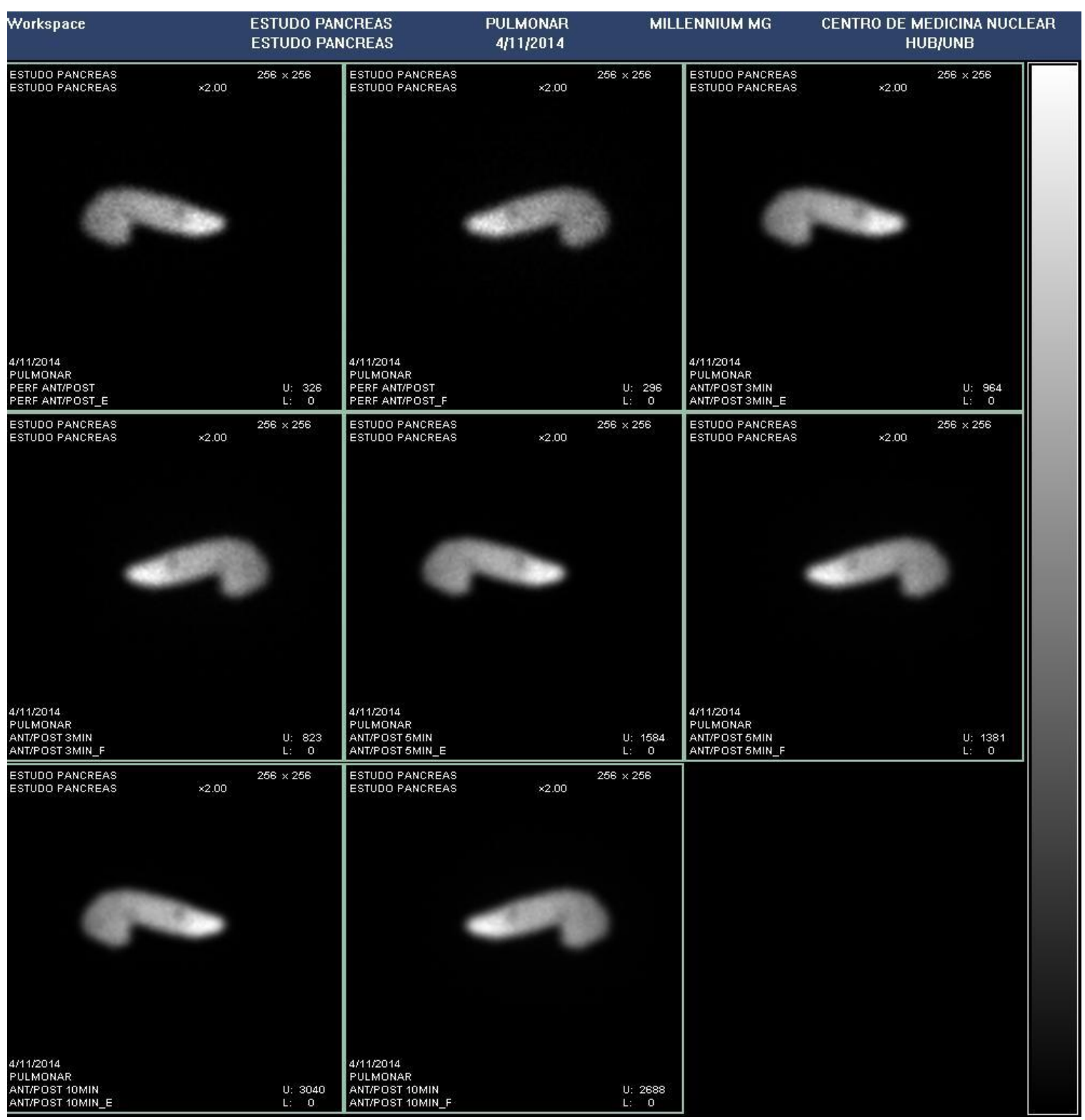

Figura 23 - Imagens Estáticas (Anterior/Posterior) do Phantom do Pâncreas. Fonte: Acervo Pessoal. 
GENERAL SPECT

Slice Review

ESTUDO PANCREAS

ESTUDO PANCREAS

PULMONAR

CENTRO DE MEDICINA NUCLEAR

HUBIUNB

15

21

27

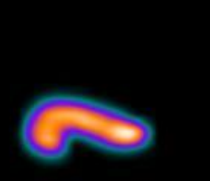

33

39

45

Anterior to Posterior

Figura 24 - Imagem cintilográfica do primeiro protótipo do Phantom do Pâncreas.

Fonte: Acervo Pessoal.

As imagens apresentaram, nitidamente, os simuladres de hemangioma evidenciando regiões de menor e maior captação da radiação gama. A Figura 25 mostra os simuladores de hemangiomas.

52 


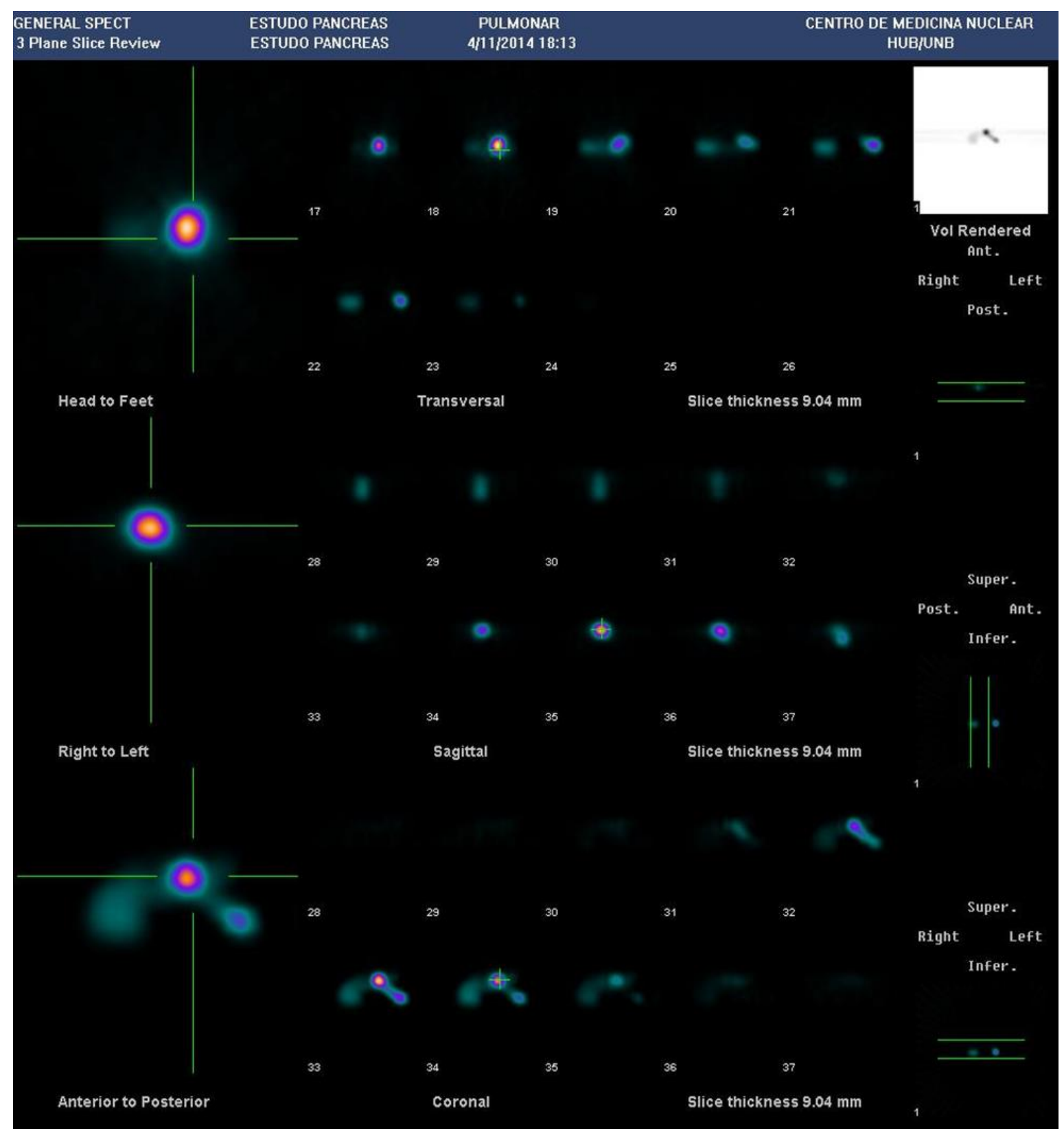

Figura 25 - Imagem dos simuladores de hemangioma.

Fonte: Acervo Pessoal.

Como mencionado no Capítulo 3 , logo após a construção do segundo protótipo do objeto simulador antropomórfico do pâncreas, imagens estáticas foram realizadas para definição de protocolo de aquisição de imagens. No entanto, para assegurar o bom desempenho da câmara de cintilação utilizada, testes de controle de qualidade foram realizados. A seguir são mostrados os resultados obtidos nos testes de controle de qualidade da câmara de cintilação. 
A Figura 26 e a Figura 27 apresentam o gráfico obtido pelos detectores 1 e 2, respectivamente, ao verificar a radiação natural do ambiente, também conhecida como radiação de fundo (ou background).

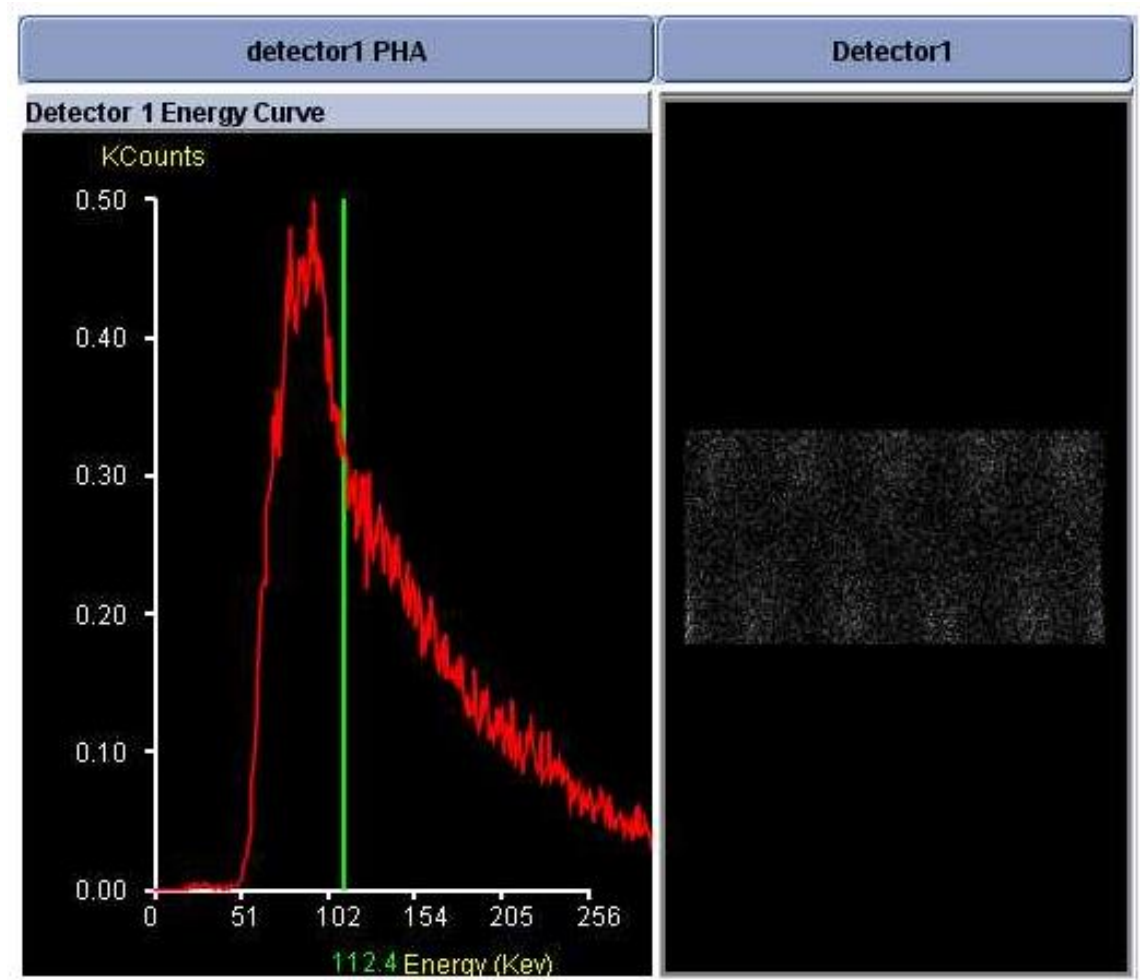

Figura 26 - Background detector 1 .

Fonte: Acervo Pessoal. 


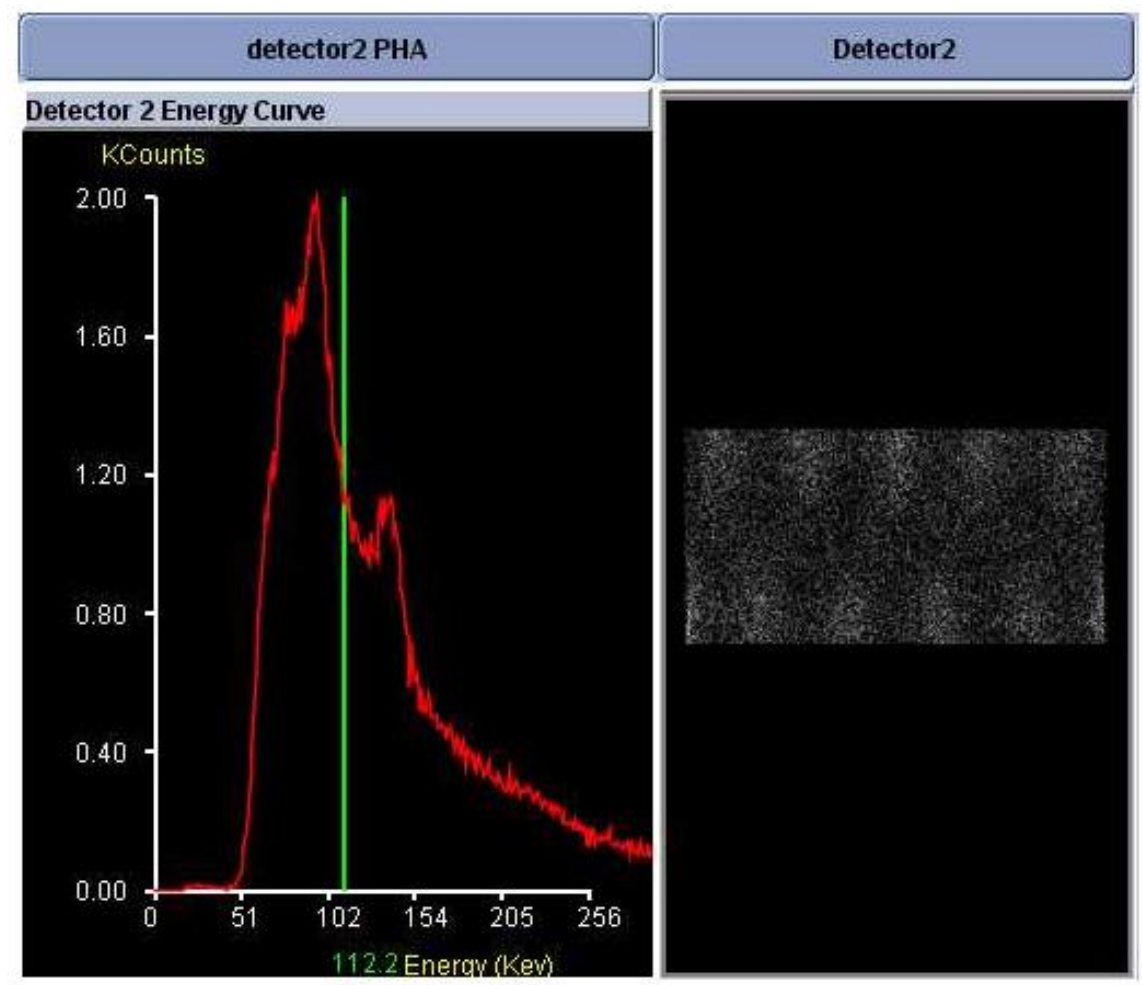

Figura 27 - Background detector 2.

Fonte: Acervo Pessoal.

Logo após a verificação da radiação de fundo do ambiente, foi realizado o teste para análise do centro de rotação. Os gráficos apresentados a seguir e a Tabela 3 mostram que os resultados obtidos permaneceram dentro da faixa recomendada pelo manual do fabricante.

Tabela 3: Resultados obtidos no teste de Centro de Rotação

\begin{tabular}{|l|l|l|l|}
\hline Name & Value & Status & Rule \\
\hline Delta X - Detector 2 & $-0.10710 \mathrm{~mm}$ & Passed & $>=-0.75$ and $<=0.75$ \\
\hline Delta Y - Detector 2 & $0.24320 \mathrm{~mm}$ & Passed & $>=-0.75$ and $<=0.75$ \\
\hline Delta X - Detector 1 & $-0.56799 \mathrm{~mm}$ & Passed & $>=-0.75$ and $<=0.75$ \\
\hline Delta Y - Detector 1 & $0.00000 \mathrm{~mm}$ & Passed & $<=0.0$ \\
\hline
\end{tabular}

Fonte: Acervo Pessoal. 
$X$ Deviation from fit Detector 1 (blue) radius $=338.5$, Detector 2 (red) radius $=338.5$

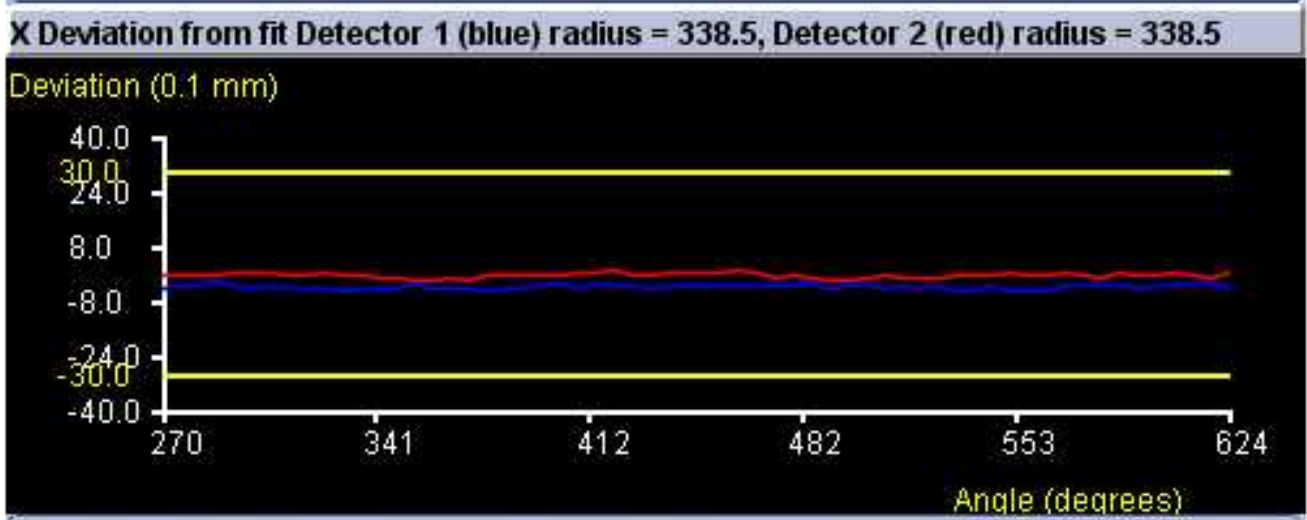

Y Deviation from fit Detector 1 (blue) radius $=338.5$, Detector 2 (red) radius $=338.5$

Y Deviation from fit Detector 1 (blue) radius $=338.5$, Detector 2 (red) radius $=338.5$

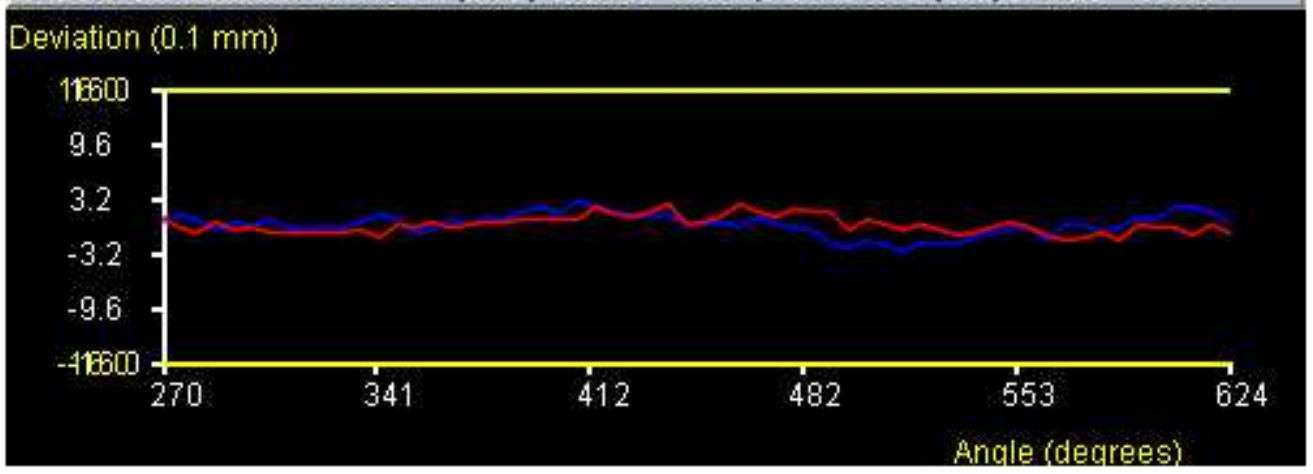

Figura 28 - Gráfico apresentando o resultado do teste de Centro de Rotação. Fonte: Acervo Pessoal.

Além de verificar o centro de rotação, testes de resolução energética, uniformidade e resolução espacial também foram realizas. A Figura 29 apresenta o gráfico obtido pelo detector 1 durante a realização destes testes. 


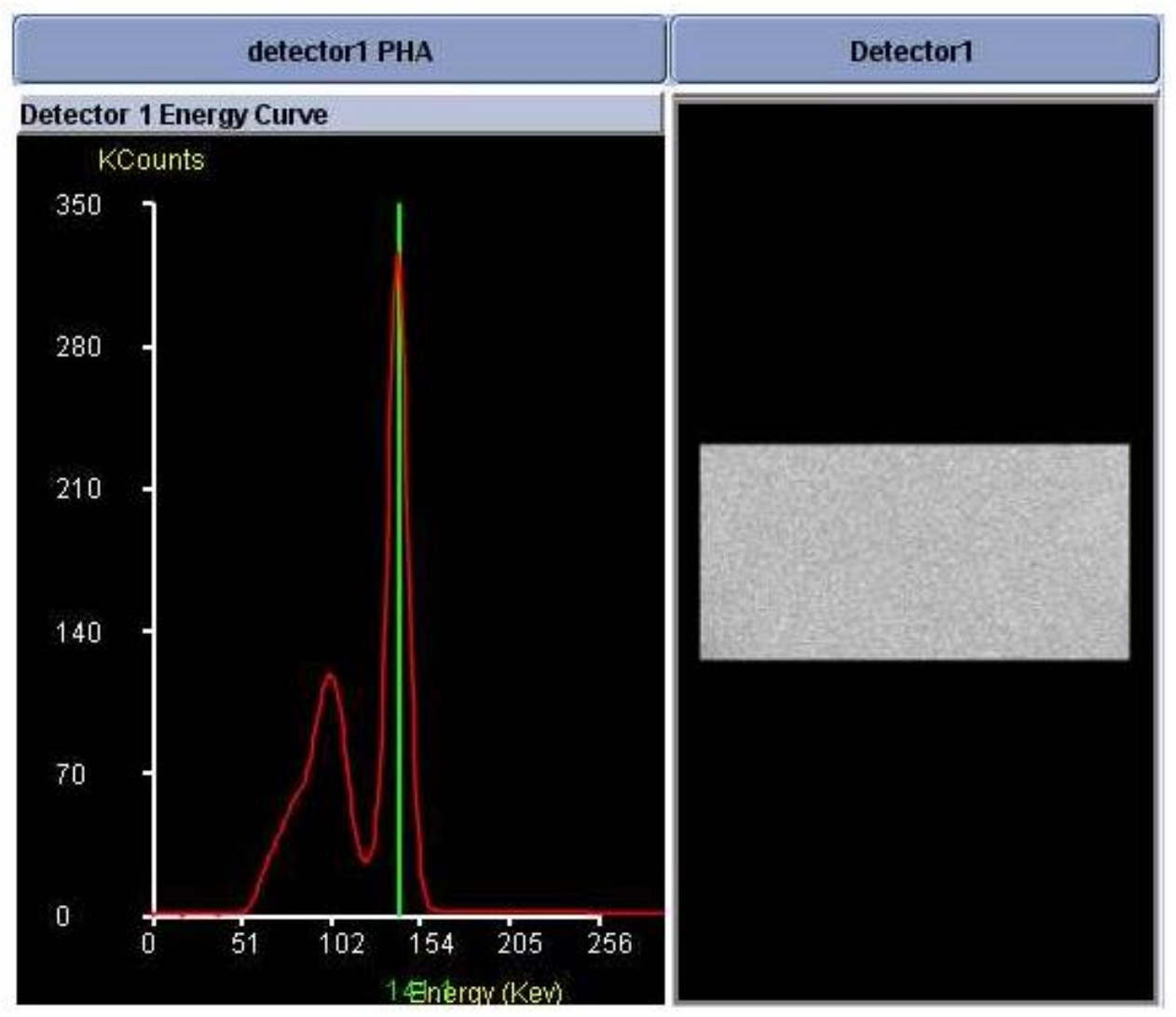

Figura 29 - Gráfico apresentando a curva energética do detector 1.

Fonte: Acervo Pessoal.

$\mathrm{O}$ pico mais alto apresenta a faixa de energia do ${ }^{99 \mathrm{~m}} \mathrm{Tc}(140 \mathrm{KeV})$, radionuclídeo utilizado para realização dos testes. $\mathrm{O}$ pico mais baixo representa os raios $\mathrm{X}$ originados da interação dos raios gamas emitidos pela fonte com o colimador de chumbo. É possível notar, ainda, que a imagem apresenta uniformidade e resolução, sem a presença de manchas escuras.

Após a realização dos testes de controle de qualidade, verificou-se que a câmara de cintilação apresentava um bom desempenho, com todos os resultados obtidos dentro da faixa recomenda pelo fabricante.

Durante a aquisição das imagens estáticas do phantom do pâncreas observou-se que as imagens adquiridas com matriz de 64 x 64 pixels, fator de ampliação 1 e janela energética de 5\% apresentou perda na resolução espacial em função da quantidade de pixels da matriz. A perda da resolução impossibilitou a identificação dos nódulos presente do objeto simulador antropomórfico. A matriz 128 x 128 pixels também não apresentou uma resolução espacial com identificação satisfatórias dos nódulos. Desse modo, observou-se que a visibilidade dos nódulos foi com a matriz 256 x 256 pixels e com a janela energética 
de 10\%. A Figura 30 apresenta a imagem do objeto simulador antropomórfico do pâncreas na matriz de $256 \times 256$ pixels.

A perda da capacidade de detecção dos nódulos foi observada, também, através da alteração da distância recomendada pelo protocolo de aquisição de imagem, ou seja, as imagens que são obtidas com distâncias maiores que $5 \mathrm{~cm}$ do objeto simulador e detector da câmara de cintilação apresentaram baixa nitidez nos detalhes das estruturas anatômicas. Desse modo, as simulações apresentaram resultados satisfatórios para o treinamento dos profissionais, mostrando assim, que o posicionado da fonte-detector é extremamente importante para aquisição de imagens, sem que haja necessidade da repetição de exames com pacientes. Além disso, o resultado da simulação corrobora que o uso de objeto simulador de órgãos pode reduzir as dúvidas no momento da aquisição da imagem com o paciente. A Figura 30 apresenta a imagem do objeto simulador antropomórfico numa distancia de $5 \mathrm{~cm}$ do detector da câmara de cintilação.

Os resultados obtidos com a matriz de 256 x 256 pixels com os fatores de ampliação de 1, 1,3, 1,5 e 2,0, conhecido também como zoom, apresentou resultado satisfatório na imagem do objeto simulador antropomórfico de pâncreas com fator de ampliação 1. Vale destacar que a matriz, a janela energética e o fator de ampliação são considerados extremamente importantes no que tange a qualidade da imagem e o treinamento dos profissionais. Desse modo, podem-se obter melhores resultados na visualização dos estudos para órgão e achados utilizando os parâmetros físicos recomendados pelos protocolos da agencia regulamentadora e fabricante.

As imagens adquiridas no sistema possibilitaram a visualização dos nódulos frios e quentes de 0,5 mm. Tais imagens mostraram nitidamente os nódulos em diversas posições. Além disso, observou-se que a simulação dos nódulos poderá ajudar significativamente no treinamento dos profissionais, mostrando os nódulos mais e menos captantes. 


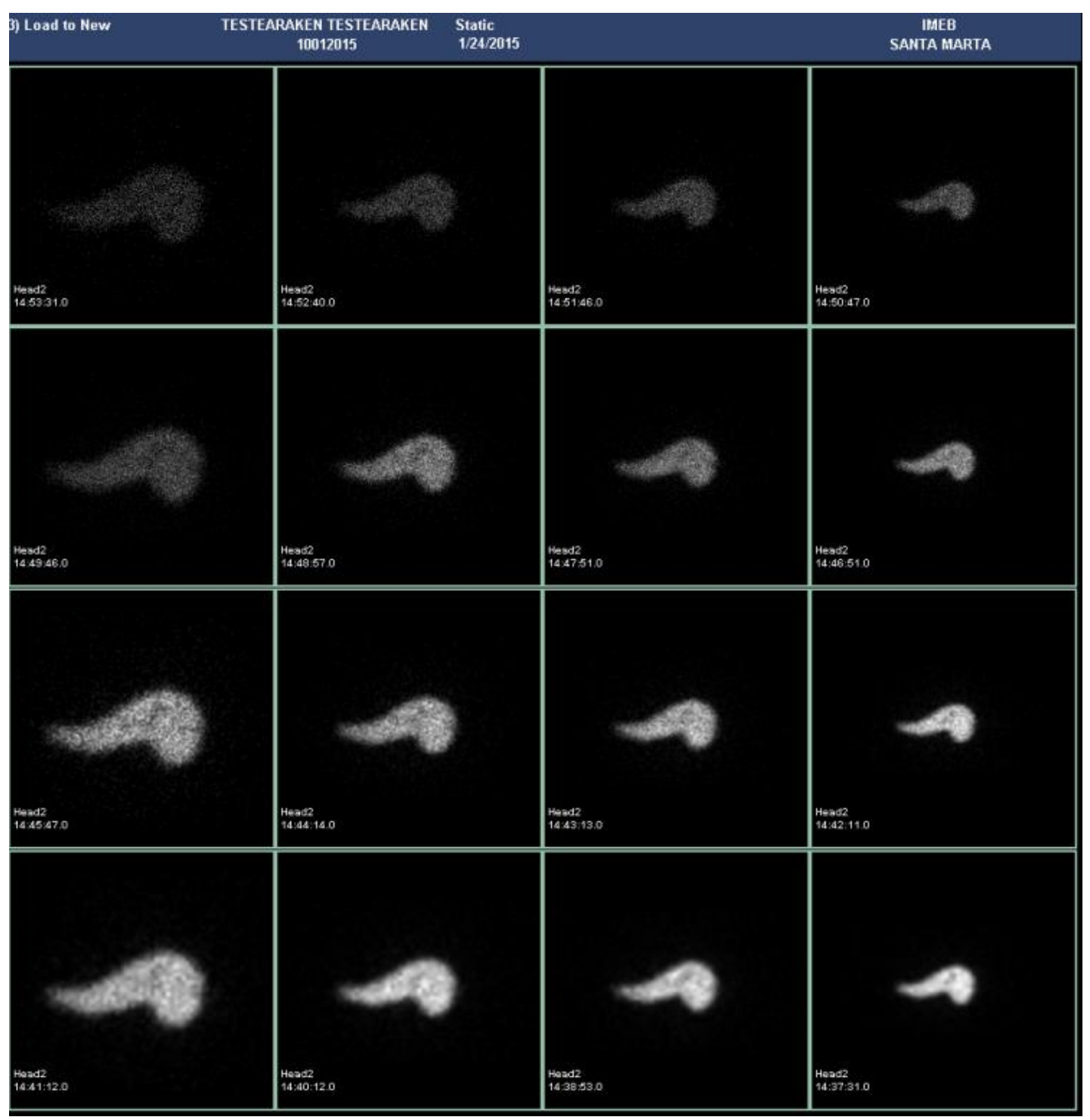

Figura 30 - Imagens estáticas (Anterior/Posterior) do segundo protótipo do objeto simulador do Pâncreas. Fonte: Acervo Pessoal. 


\section{CONCLUSÃO}

As imagens obtidas neste estudo revelaram características geométricas do corpo, e os detalhes dos nódulos que foram inseridos para análise da dose e captação do radionuclídeo. As imagens obtidas possibilitaram o estudo dos detalhes anatômicos do phantom do pâncreas e nódulos quentes e frios. Notou-se que o método de imagem da radiologia revela, ainda que com maior precisão, somente detalhes anatômicos, enquanto as imagens de medicina nuclear, além de detalhes anatômicos, revelam características sobre a funcionalidade do órgão. É importante, ainda, ressaltar que o objeto simulador foi produzido com material de baixo custo financeiro e podem ser facilmente construídos.

As imagens obtidas pela câmara cintilográfica do objeto simulador do pâncreas, na matriz 256 x 256 pixels, janela energética de $10 \%$ e o fator de ampliação 1 apresentaram resultados bastante satisfatórios. Os estudos realizados demonstraram que o objeto simulador antropomórfico de pâncreas confeccionado poderá ser utilizado para avaliação de equipamentos de aquisição de imagem, por exemplo, para testes de resolução espacial, assim como para treinamento de profissionais com demonstração das matrizes 64, 128, 256 e 512 pixels, assim como, a janela energética 5, 10, 15 e 20\% e o fator de ampliação de 1,0, $1,3,1,5$ e 2,0 .

Assim, além de testes com a aquisição de imagens nos equipamentos da medicina nuclear, verifica-se que as simulações com o phantom do pâncreas podem contribuir para educação continuada de profissionais da medicina nuclear, aperfeiçoando a habilidade dos mesmos na identificação de nódulos frios e/ou quentes. 


\section{TRABALHOS FUTUROS}

Considerando a temática deste trabalho, verifica-se que é possível a contribuição eficaz da Física de modo a propiciar aos pacientes, submetidos a exames de Medicina Nuclear, um equilíbrio entre a menor dose de radiação absorvida e a qualidade dos resultados obtidos em técnicas de diagnóstico por imagem.

A proposta inicial partiu da importância do uso de objetos simuladores físicos e antropomórficos para controle de qualidade em Medicina Nuclear. No entanto, o foco permaneceu, apenas, no desenvolvimento de dois objetos simuladores antropomórficos do pâncreas para estimativas e definição de protocolos de aquisição de imagens.

Intenta-se, em trabalhos futuros, a possibilidade do desenvolvimento de um objeto simulador antropomórfico do pâncreas construído na impressora 3D. Além disso, é possível desenvolver um objeto simulador físico baseado em imagens de tomografia.

É importante mencionar, também, o interesse no desenvolvimento de um radiofármaco específico para o pâncreas, para diagnóstico precoce de qualquer anomalia presente no órgão.

Este trabalho, como um todo, indiscutivelmente constituiu o início de prováveis estudos sobre a temática, reforçando em outros níveis de pesquisa científica a importância da intervenção da Física como fator de contribuição à saúde. 


\section{REFERÊNCIAS BIBLIOGRÁFICAS}

AAPM. Quantization of SPECT Performance - Report No. 52, 1995.

CERQUEIRA, R. A. D.; CONCEIÇÃO, B. M.; TEIXEIRA, C. H. C.; MOTA, C. D.; RODRIGUES, T. M. A.; MAIA, A. F. Construção de um Objeto Simulador Antropomórfico de Tórax para Medidas de Controle da Qualidade da Imagem em Radiodiagnóstico. Revista Brasileira de Física Médica. p. 39-42, 2011.

CHERRY, Simon R.; SORENSON, James A.; PHELPS, Michael E. Physics in Nuclear Medicine. $3^{\text {rd }}$ ed. Philadelphia: Saunders, 2003.

CNEN-COMISSÃO NACIONAL DE ENERGIA NUCLEAR (CNEN-NN-3.05. Requisitos de radioproteção e segurança para serviços de medicina nuclear. Rio de Janeiro, 1996).

EISBERG, Robert; RESNICK, Robert. Física Quântica. 29a Reimpressão. Rio de Janeiro: Elsevier, 1979.

FERREIRA, Fernanda Carla Lima. Desenvolvimento de Objetos Simuladores para Medicina Nuclear. São Cristóvão: UFS, 2011. Tese. Universidade Federal de Sergipe, 2011.

FERREIRA, F. C. L.; SOUZA D. do N. Aceitabilidade de um Futuro Banco de Objetos Simuladores para Controle de Qualidade em Medicina Nuclear. Radiol Bras. 2011 Mar/Abr; 44(2):104-108.

FURNARI, Laura. Controle de Qualidade em Radioterapia. Revista Brasileira de Física Médica. Vol. 3, n.1, p. 77-90, 2009.

GARCIA, Eduardo A. C. Biofísica. $2^{\mathrm{a}}$ reimpr. da 1ª ed. São Paulo: SARVIER, 2002.

GUYTON, A. C.; HALL, J. E. Tratado de Fisiologia Médica. 11ª ed. Elsevier, 2006.

IAEA. Quality Control of Nuclear Medicine Instruments. Vienna, 1991.

INCA. Qualidade em Radioterapia. Disponível em: <http://www.inca.gov.br>. Acesso em: 12 de fevereiro de 2014

INCA. Estimativa 2010: incidência de câncer no Brasil. Rio de Janeiro: INCA, 2009

KARP, Gerald. Biologia Celular e Molecular: conceitos e experimentos. $3^{\text {a }}$ ed. São Paulo: Manole, 2005.

LIMA, M. A. G.; BARBOSA, L. N. F., SOUGEY, E. B. Avaliação do impacto da qualidade de vida em Pacientes com Câncer de Laringe. Rev. Sociedade Brasileira de Psicologia Hospitalar. Vol. 14, n.1, p. 18-40, 2011. 
MACHADO, M. M.; ROSA, A. C. F.; BARROS, N. de; CERRI, G. G. Ultra-Sonografia Endoscópica (USE) do Pâncreas. Radiologia Brasileira, v. 35(4), p. 217-218, 2002.

Ministério da Saúde. Diretrizes de Proteção Radiológica Em Radiodiagnóstico Médico e Odontológico. Brasília; 1998 (Portaria 453).

OKUNO, Emico; YOSHIMURA, Elisabeth Mateus. Fisica das Radiações. São Paulo: Oficina de Textos, 2010.

OKUNO, E.; CHOW, C.; CALDAS, I. L. Física para Ciências Biológicas e Biomédicas. São Paulo: HARBRA, 1982.

OKUNO, Emico. Radiação: Efeitos, Riscos e Benefícios. São Paulo: HARBRA, 1988.

OLIVEIRA, R.; SANTOS, D.; FERREIRA, D.; COELHO, P.; VEIGA, F. Preparações Radiofarmacêuticas e suas Aplicações. Revista Brasileira de Ciências Farmacêuticas. Vol. 42, n.2, p. 151-165, abr./jun., 2006.

OLIVEIRA, Jarbas Rodrigues de. Biofísica para Ciências Biomédicas. Porto Alegre: EDIPUCRS, 2002.

PAIXÃO, Elemarcia Martins da Silva. Variação do Peso Corporal e Fatores Associados em Pacientes com Câncer Submetidos à Radioterapia. Brasília: UnB, 2010,84p. Dissertação, Nutrição.Universidade de Brasília, Brasília, 2010.

POWSNER, R. A.; POWSNER, E. R. Essential Nuclear Medicine Physics. Blackwell publishing, 2006.

RUSSELL, John B. Química Geral. Vol. 2. $2^{\text {a }}$ ed. São Paulo: Pearson Makron Books, 1994.

SCAFF, Luiz Alberto Malaguti. Física da Radioterapia. São Paulo: Sarvier, 1997.

THRALL, James H.; ZIESSMAN, Harvey A. Medicina Nuclear. $2^{\text {a }}$ ed. Rio de Janeiro: Guanabrara Koogan, 2003.

TILLY JUNIOR, João Gilberto. Física Radiológica. Rio de Janeiro: Guanabara Koogan, 2010.

YOSHIMURA, Elisabeth Mateus. Física das Radiações: interação da radiação com a matéria. Revista Brasileira de Física Médica. Vol. 3, n. 1, p57-67, 2009. 
ANEXOS 


\title{
Anthropomorphic Phantom of the Pancreas for Scintillation Camera Tests
}

\author{
H.C.M. Silva ${ }^{1}$, F. C. L. Ferreira ${ }^{2}$, L.M. Brasil ${ }^{1}$, G.V.S. Luz ${ }^{1}$, and L.X. Cardoso ${ }^{1,2}$ \\ ${ }^{1}$ University of Brasilia at Gama (UnB-FGA)/Postgraduate Program in Biomedica Engineering, Brasilia, Brazil \\ ${ }^{2}$ Federal University of South and Southeast of Pará, Marabá, Brazil
}

\begin{abstract}
It is well known that several clinical procedures involving the use of ionizing radiation has made the radiation physics indispensable in modern medicine. In nuclear medicine, for example, the so-called radiopharmaceuticals are used for diagnostic and treatment of various diseases. For diagnosis purposes, particularly, it is important that the images reveal, with highest sharpness, relevant details of any anomaly. In this regard, the objective of this work is the development of a phantom for quality control optimization in scintillation cameras and thus the acquisition of images that are reliable for the diagnosis, besides the dose control so that the radiation is used to efficiently to the quality and definition in image processing. The present purpose reveals that the anthropomorphic phantom pancreatic object can be used to optimize image acquisition equipment, especially for spatial resolution tests, and enable the professionals of Nuclear Medicine training.
\end{abstract}

Keywords - Nuclear Medicine, Phantom of the Pancreas, Quality Control.

\section{INTRODUCTION}

Nowadays, the increasing number of clinical procedures involving the use of ionizing radiation reveals a scenario that elevates the radiation physics to indispensable condition in modern medicine. In the nuclear medicine, particularly for diagnostic purposes, these medical procedures has aim to obtain images by inserting a radionuclide associated with a drug known as a radiopharmaceutical. The radiopharmaceuticals have affinity with the tissue or organ under study [1].

It is noteworthy that the images must have precision in geometry of the organ, revealing the details of anatomical structures and ensuring lower radiation for patient exposure. In this context, the phantoms play a key role in optimizing the quality control of scintillation cameras allowing studies about doses of radiation administered to the patient in contrast to the image processing quality and spatial resolution, i.e. images reliable for diagnostic purposes [2]. Some quality control tests are considered essential for ensuring medical image quality and reduce the dose absorbed by patients and professionals. However, it is unacceptable that such tests be performed directly on patients, since the use of ionizing radiation can harm their health, requiring the consent of the patient and the ethics committee. Furthermore, the mor- phology changes of the human body would make the tests analysis quite complex [3].

Thus, the International Atomic Energy Agency (IAEA) recommends use a phantom for the quality control of scintillation cameras. According to the recommendations of the IAEA-TECDOC-602 [4], are used physical phantoms suitable for achieving the field uniformity tests, linearity and spatial resolution of scintillation cameras, as well as anthropomorphic phantoms for quality control and training of professionals [3]. These objects can have simple geometry (object physical simulator) without geometric design of the organ and are made in the boxes format, or may have similar geometry to the real organ shape (object anthropomorphic phantom). Both are used to simulate and study the behavior of radiation in the body and thus allow an estimation of medical images, quality control of image acquisition devices and adequacy of radiation dose absorbed by the patient [5].

As previously mentioned, the importance of organ phantoms is highlighted by some researchers. One can show some works, such as the evaluation of a quality control phantom for digital chest X-ray [6], the application of a simple phantom to evaluate the effects of dose reduction and image quality in chest X-rays [7] and the construction of an anthropomorphic phantom of the chest for quality control in diagnostic radiology [3].

However, the physiological significance of pancreas motivated the choice of the organ for the development of phantom. The pancreas can be divided anatomically into four parts: head, neck, body and tail. Contains millions of acini coated with glandular secretory cells responsible for secretion of digestive enzymes to the duodenum. Besides your digestive functions, it secretes two important hormones (insulin and glucagon) responsible for the normal regulation of the metabolism of glucose, lipids and proteins. These hormones are secreted directly into the blood by the islets of Langerhans [8].

Besides to its physiological importance, another motivation for the development of an anthropomorphic phantom of the pancreas is that the increased incidence of individuals tumors in this organ has increased in recent years [9], and there isn't examination specific image to the pancreas, making it difficult early diagnosis of any present anomaly, since it is located in the abdominal cavity behind the stomach [8]. 
In this sense, it is considered important to use phantoms to ensure the image quality in nuclear medicine and so that all clinical procedures are performed according to established rules and standards by the competent organizations. Therefore, it is extremely important the use of phantoms for quality control, image acquisition protocol and also the training of professionals. Besides it is considered interesting that the objects simulators can be produced nationally, that represent a low cost compared to imports, which are easy to fabricate and in the future, are available for many nuclear medicine services.

The objective of this research is to develop an anthropomorphic phantom of the pancreas to perform quality control in scintillation cameras and train professionals in the identification of hot nodules and/or cold nodules. It is intended also spark interest in other scientific research for the development of a radiopharmaceutical that has specificity to the pancreas and, consequently, the possibility of an diagnostic examination for specific image of the pancreas. In the following sections, the matter will be discussed in more detail.

\section{Methodology}

For the construction of the anthropomorphic phantom of the pancreas was used self-curing acrylic and alginate, both for use in dentistry. The alginate was prepared following the manufacturer's instructions. Was added water in the proportions recommended on the packaging material so that the material stayed pasty texture. After preparation of the pasta, it was immediately used for molding the pancreas.

After obtaining the form of the pancreas phantom, the curing acrylic was prepared (by mixing the polymer and monomer) in the ratio recommended by the manufacturer. The material was distributed in alginate mold, being removed after the complete hardening.

For the simulation of the nodules, styrofoam balls encased in catheters were used to simulate the vascularization of tumors. It is important to mention that during the process of the acrylic preparing the environmental temperature was maintained near $23{ }^{\circ} \mathrm{C}$. The Fig. 1 shows the anthropomorphic phantom of the pancreas finalized.

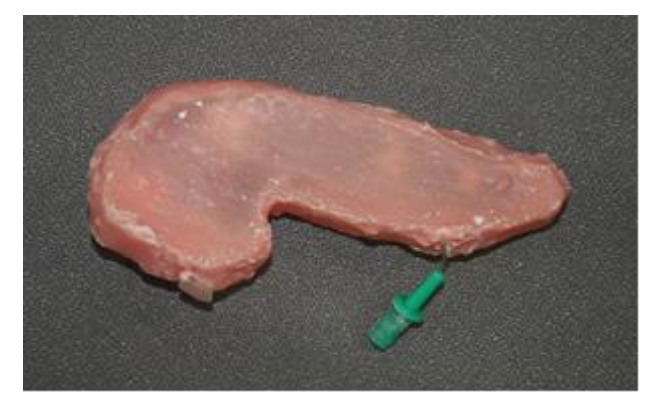

Fig. 1 Anthropomorphic Phantom of the Pancreas

After the construction of the anthropomorphic phantom were performed radiographic images and scintigraphic to check their morphology. We performed three steps of imaging.

In the first stage, held at the radiology sector of Climagem (Marabá, Pará/Brazil), to obtain X-ray images (Fig. 2) was inserted into the phantom $7.5 \mathrm{ml}$ of radiological contrast meglumine ioxithalamate diluted in physiologic solution.

In the second stage, performed in the nuclear medicine sector of the University Hospital of Brasilia/Brazil (HUB), was held some static and scintigraphic images. The phantom was filled with water and ${ }^{99 \mathrm{~m}} \mathrm{Tc}$ for these images. Then, the phantom was placed in scintillation camera for capturing statics images (anterior and posterior) with an acquisition 3, 5 and 10 minutes, as shown in Fig. 3. Still filled with ${ }^{99 \mathrm{~m}} \mathrm{Tc}$, tomography images were obtained using lung Protocol (Fig. 4).

Also in the HUB, the third step was carried out by $99 \mathrm{mTc}$ inserting on the hemangiomas simulator, simulating the vascularization of tumors and showing regions with higher uptake and lower uptake of gamma radiation (Fig. 5).

\section{REsUlts AND DisCUSSION}

In this study we observed that the images obtained revealed geometrical characteristics of the body and details of the nodules that were entered for dose analysis and uptake of the radionuclide. With these images is possible to study the anatomical details of the pancreas phantom and hot and cold nodules. Note that the imaging method of Radiology (Fig. 2) only revealed anatomical details, however, more precisely. 


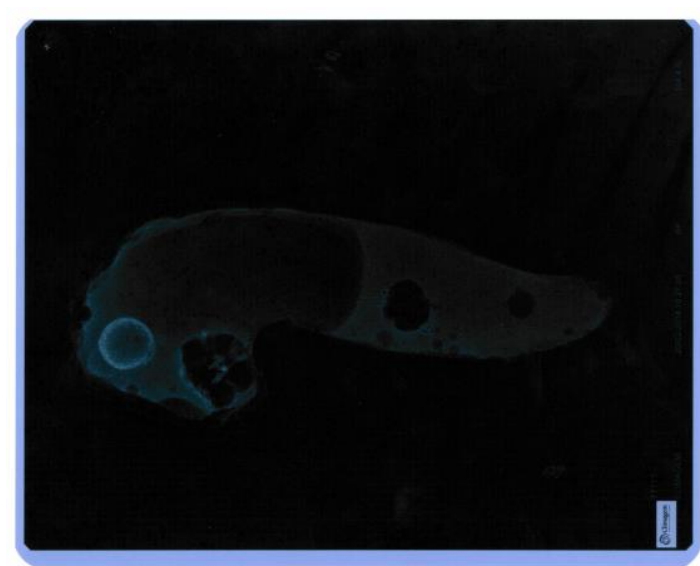

Fig. 2 Anthropomorphic phantom radiography Pancreas

In nuclear medicine imaging methods (Fig. 3 and Fig. 4), besides anatomical details, you can see details on organ function. It is also important to emphasize that the phantom was produced with low financial cost, and could be easily reproduced.

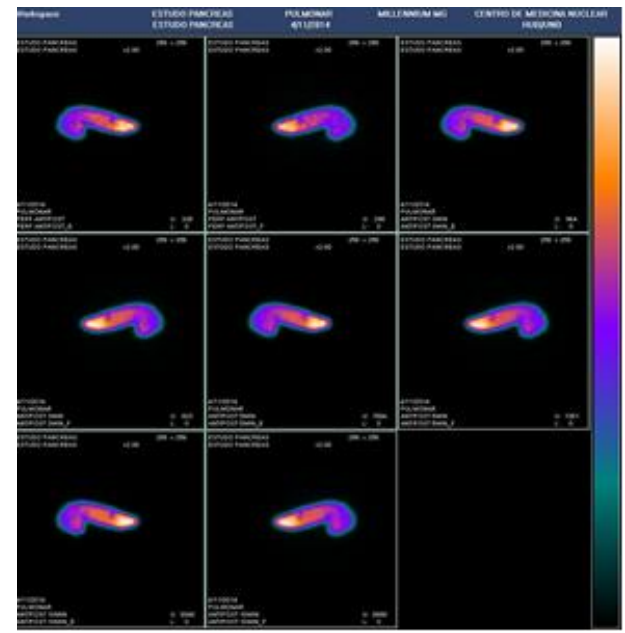

Fig. 3 Presentation of image acquisition anthropomorphic phantom of the pancreas in the matrix of $256 \times 256$ pixels

In assessing the sharpness of the images was observed the acquisitions with array of $32 \times 32$ pixels, magnification factor 1 and energy window of $5 \%$ showed loss in spatial resolution according to the number of pixels of the matrix. The loss of resolution prevented the identification of nodules presented in the anthropomorphic phantom of the pancreas. The matrices $64 \times 64$ and $128 \times 128$ pixels did not present a spatial resolution with satisfactory identification of nodules. Thus, it was observed that the best visibility of the nodes of the phantom was in the array $256 \times 256$ pixels and a $10 \%$ energy window. The Fig. 3 shows the image of the anthropomorphic phantom of the pancreas in the array of $256 \times 256$ pixels.

The change in distance (recommended by the image acquisition protocol) between the phantom and the scintillation camera detector showed loss of nodules identification capacity, i.e., the images obtained with distances greater than $5 \mathrm{~cm}$ between the phantom and the scintillation camera detector showed low sharpness in the details of anatomical structures. Thereby, the simulations showed satisfactory results to contribute to the training of professionals, thus showing that the source-detector positioned is extremely important for the acquisition of images without the need of repeat examinations with patients. In addition, the simulation results confirm that the use of organs phantom can reduce the doubts at the time of image acquisition. The Fig. 4 shows the image of the anthropomorphic phantom in a distance of $5 \mathrm{~cm}$ from the scintillation camera detector.

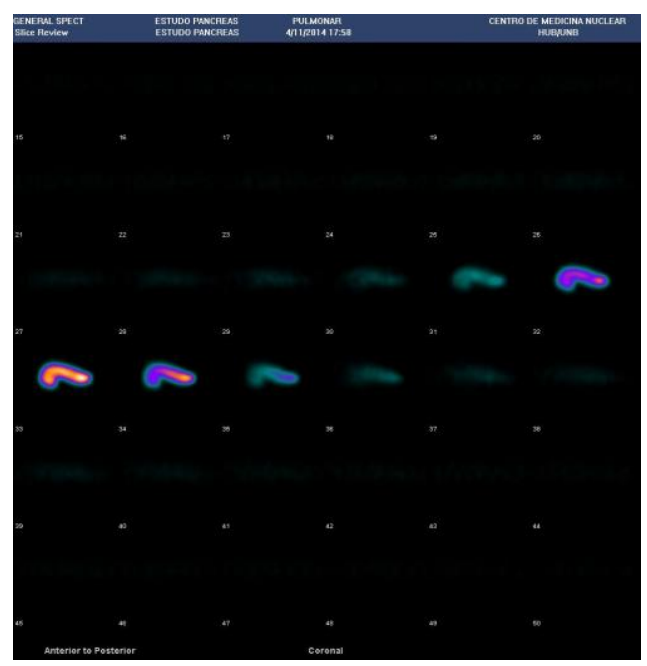

Fig. 4 Presentation of image acquisition of the anthropomorphic phantom of the pancreas in distance of $5 \mathrm{~cm}$ from the scintillation camera detector

The results obtained with the matrix of $256 \times 256$ pixels with a magnification factor of $1 ; 1.3 ; 1.5$ and 2.0 , also known as zoom, with satisfactory results in the image of the anthropomorphic phantom when the magnification factor was 1 . However, did not change the array, as if there were reduction in matrix expansion the zoom could be 1.3 , because it is a small simulator with detailed anatomical structures - the hot and cold nodules. Note that the matrix, the energy window and the zoom factor are considered extremely important when it comes quality image and training of professionals. Thus, one can obtain better results in the 
display of the studies for organ and findings using the physical parameters recommended by the protocols of the regulatory agency and the manufacturer.

The acquired images enabled the visualization hot and cold nodules of $0.5 \mathrm{~mm}$. These images clearly showed the nodules in different positions. Besides, can be noted that the simulation of the nodules can significantly help in the training of professionals, showing the nodules more and less exposed to gama radiation (Fig. 5).

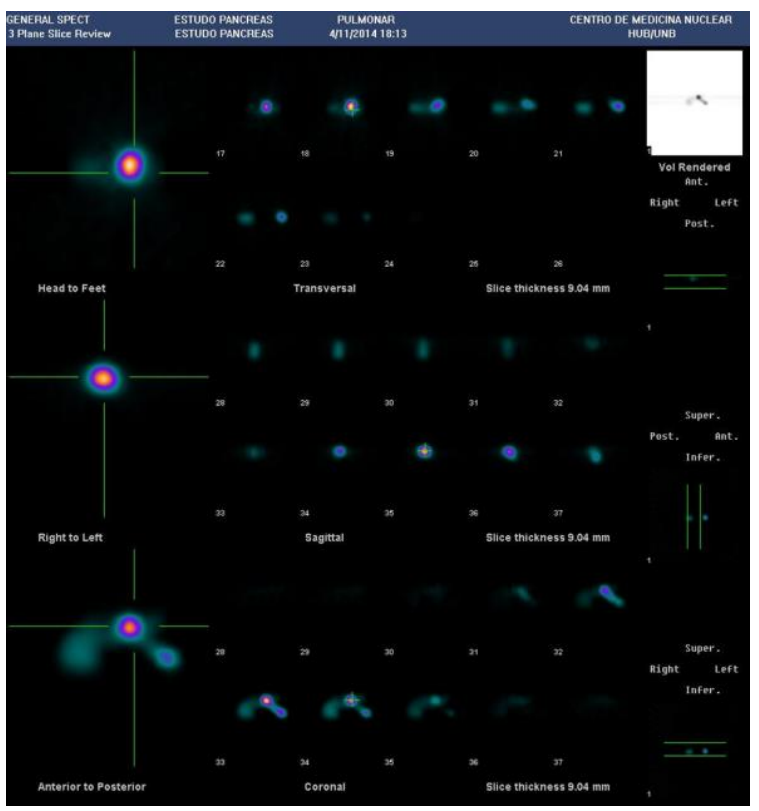

Fig. 4 Simulators of the hot nodules on scintigraphy

\section{Conclusions}

The images obtained from the phantom of the pancreas in the matrix $256 \times 256$ pixels, energy window of $10 \%$ and the magnification factor 1 showed promising results. The studies performed in this work demonstrated that the anthropomorphic phantom of the pancreas can be used to evaluate image acquisition devices, in particular for spatial resolution tests, as well as training of professionals.

Thus, in addition to the testing of nuclear medicine devices, is important noted that the simulations using the phantom of the pancreas may contribute to continuing edu- cation of the professionals in this area, improving the ability in identifying nodules cold and/or hot nodules.

\section{ACKNOWLEDGMENT}

The authors acknowledge financial support from the Brazilian agency CAPES and those responsible for the nuclear medicine service of the Hospital (HUB).

\section{Conflict of InTEREST}

The authors declare that they have no conflict of interest.

\section{REFERENCES}

1. Oliveira R, Santos D, Ferreira D, Coelho P, Veiga F. (2006) Radiopharmaceuticals and applications. Braz J Pharm Sci 42:151165

2. Ferreira F, Souza D. (2011) Acceptability of a future phantoms bank for quality control in nuclear medicine. Braz Radiol 44:104-108

3. Cerqueira R, Maia A. (2011) Development of an anthropomorphic thorax phantom for image quality control measurements in diagnostic radiology. Braz J Med Phys 4:39-42

4. IAEA-TECDOC-602 (!991) Quality control of nuclear medicine instruments. IAEA, Vienna

5. Xu X G. (2014) The Phantoms of Medical and Health Physics. Springer, New York

6. Mah E, Samei E, Peck D J. (2001) Evaluation of a quality control phantom for digital chest radiography. Journal of Applied Clinical Physics, v.2, n.2.

7. Egbe N O, Heaton B, Sharp P F. (2010) Application of a simple phantom in assessing the effects of dose reduction on image quality in chest radiography. Radiography, 16:108-114

8. GUYTON A C, HALL J E. (2006) Textbook of medical physiology. Elsevier, Philadelphia

9. INCA at http://www.inca.gov.br

Author: Halaine Crisitine Mariano Silva

Institute: University of Brasilia

CEP: 72444 - 240

City: Brasília

Country: Brazil

Email: halaine.fisica@gmail.com 